\title{
Revision of the ant genus Calyptomyrmex (Hymenoptera: Formicidae) in South-east Asia and Oceania
}

\author{
STEVEN O. SHATTUCK \\ CSIRO Ecosystem Sciences, P. O. Box 1700, Canberra, A.C.T. 2601, Australia.E-mail: steve.shattuck@csiro.au
}

\begin{abstract}
The South-east Asian and Oceanian fauna of the ant genus Calyptomyrmex is revised. Sixteen species are known from this region, 14 of which are newly described. These include asper sp. n., beccarii Emery, caledonicus sp. n., danum sp. n., fragarus sp. n., fritillus sp. n., grammus sp. n., lineolus sp. n., loweryi $\mathbf{s p .}$ n., ocullatus sp. n., rectopilosus Dlussky \& Radchenko, retrostriatus sp. n., ryderae sp. n., sabahensis sp. n., sparsus sp. n. and taylori sp. n. The names emeryi Forel and glabratus Viehmeyer are synonymised under beccarii, the only widespread species in the region. All species are associated with rainforest habitats and most have been collected a limited number of times.
\end{abstract}

Key words: Hymenoptera, Formicidae, Calyptomyrmex, taxonomy, new species, Indo-Pacific

\section{Introduction}

Members of the genus Calyptomyrmex are rare ants which are most often encountered as ground foragers or in leaf litter collected from the surface of the ground. They are most commonly encountered in rainforests where they forage singly or in small numbers (Bolton, 1981) but they can occasionally be found in other forested situations as well. The few nests that have been found were in rotten wood (Shattuck, 1999; Taylor, 1991) or directly in soil (Bolton, 1981). Workers are often covered with a layer of soil, the enlarged and often spatulate hairs presumably assisting in the retention of this camouflaging material. Similar behaviours are known in many species of basicerotines as well as Stegomyrmex (Holldobler \& Wilson, 1986), this behaviour being convergent as these groups are not closely related. The majority of species of Calyptomyrmex are known from only limited numbers of collections, with even the most common having been collected fewer than 20 times. Although this rarity makes estimates of true distribution patterns problematic, it appears that most species have restricted ranges while only a single species has become widespread.

Biogeographically, Calyptomyrmex is known from Africa and India east to New Caledonia (Guenard, 2009). Baroni Urbani (1975) revised the fauna of the Indian subcontinent and Bolton (1981) the Afrotropical species while this study investigates the fauna of South-east Asia and eastward. This revision adds 14 new species, bringing the total known for the genus to 28 (Bolton et al., 2006). Taylor (1991) provided an overview of the Australian fauna, synonymised the only Australian-based name with the widespread species beccarii and outlined seven undescribed Australian species (although none were formally named). Six of these species are described here, along with an additional species, bringing the total number of species known from Australia to eight (beccarii Emery, fragarus sp. n., fritillus sp. n., grammus sp. n., lineolus $\mathbf{s p .}$ n., ocullatus $\mathbf{s p .}$., sparsus $\mathbf{s p .}$., taylori $\mathbf{s p .}$.. ). The remaining new species include one from Malaysia and the Philippines (loweryi sp. n.), five from Malaysia (asper sp. n., danum sp. n., retrostriatus sp. n., ryderae sp. n., sabahensis $\mathbf{s p .} \mathbf{n}$.) and one from New Caledonia (caledonicus $\mathbf{s p .}$ n.).

The South-east Asian fauna is similar in diversity to that of Australia, with eight species so far known (asper sp. n., beccarii Emery, danum sp. n., loweryi sp. n., rectopilosus Dlussky \& Radchenko, retrostriatus sp. n., ryderae sp. n., sabahensis sp. n.), one of these (beccarii) being shared with Australia. Given that many of these species are known from only single or a few collections it is likely that additional species exist which are yet to be encountered. Only single species are known from Papua New Guinea (beccarii) and New Caledonia (caledonicus). 


\section{Methods and abbreviations}

Size and shape characters were quantified and are reported as lengths or indices. Measurements were made with a stereo microscope using a dual-axis stage micrometer wired to digital readouts. The following measurements and indices are reported: CFW, clypeal fork width measured between the anterior-most points of the teeth; CI (cephalic index), HW/HL x 100; HL, head length in full face view, measured from a line drawn across the anterior-most points of the clypeal fork teeth to the midpoint of a line drawn across the posterior margin of the head; HW, maximum head width in full face view; ML, mesosomal length measured from the point at which the pronotum meets the cervical shield to the posterior base of the propodeal process, viewed laterally; MTL, maximum length of mid tibia, excluding the proximal part of the articulation which is received into the distal end of the femur; PetI, (petiolar index), PetW/PetL x 100; PetL, maximum length of the petiolar node in dorsal view; PetW, maximum width of the petiolar node in dorsal view ; PronW, maximum width of the pronotum in dorsal view; SI (scape index), SL/ HW x 100; SL, length of the scape (first antennal segment) excluding the basal constriction and condylar bulb.

Collections: ANIC, Australian National Insect Collection, Canberra, A. C. T.; BMNH, The Natural History Museum, London, U. K.; MCZC, Museum of Comparative Zoology, Harvard University, Cambridge, Massachusetts, U. S. A.; MHNG, Muséum d'Histoire Naturelle, Geneva, Switzerland; MNHB, Museum für Naturkunde der Humboldt-Universität, Berlin, Germany; MSNG, Museo Civico di Storia Naturale, Genoa, Italy; QMBA, Queensland Museum, Brisbane, Queensland; UASK, Institute of Zoology, Ukrainian Academy of Science, Kiev, Ukraine.

\section{Calyptomyrmex Emery}

Calyptomyrmex Emery, 1887: 471.

Type species. Calyptomyrmex beccarii Emery, 1887, by monotypy.

Diagnosis. Workers belonging to Calyptomyrmex may be separated from those of other myrmicine genera by the presence of distinct, elongate depressions (antennal scrobes) on the front of the head which contain the entire antennae when at rest and the conspicuous, broad, bilobed appendage (the clypeal fork) which projects over the rear section of the mandibles. The deep antennal scrobes and the unique configuration of the clypeus will separate these ants from all others in the region. For a more complete description see Bolton (1981).

\section{List of South-east Asian and Oceanian species}

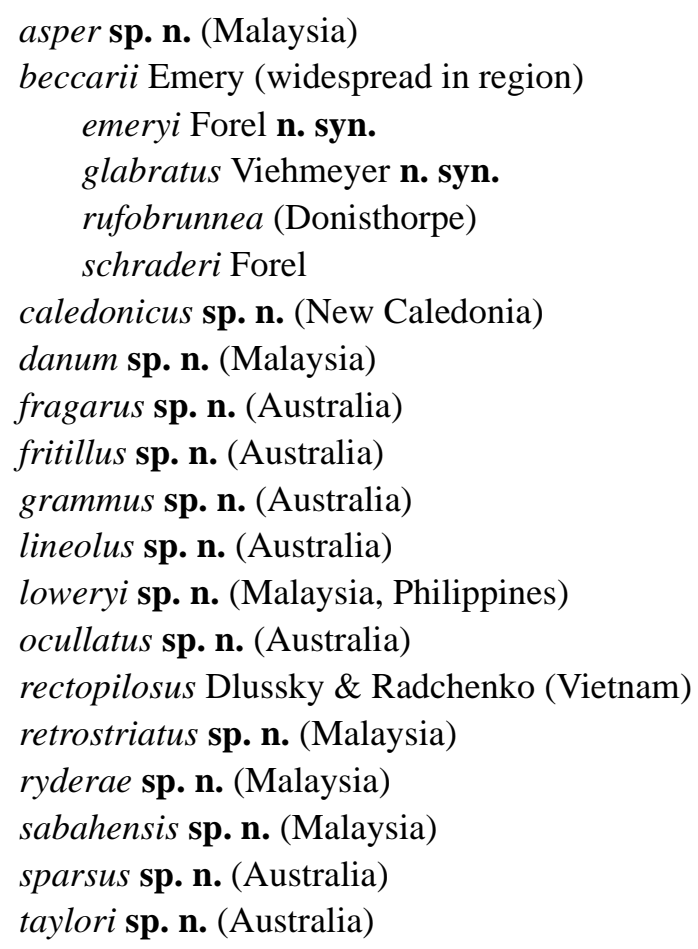




\section{Key to species of South-east Asian and Oceanian Calyptomyrmex based on workers}

1. Hairs on head and body spatulate (noticeably narrower near the body and expanded distally and with a rounded tip, Fig. 3 ) ... 2

-. Hairs on head and body thin (essentially the same width along entire length, or only slightly and gradually expanded distally,

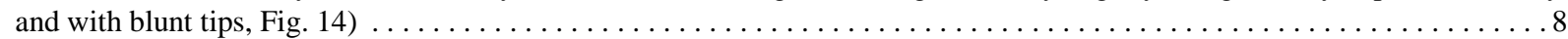

2. Gaster with low longitudinal striations running between the spatulate hairs (Australia) ............... fragarus

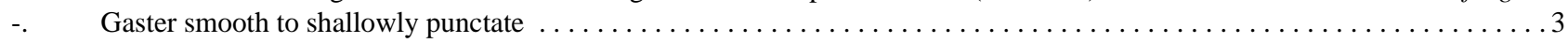

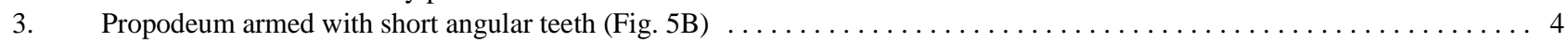

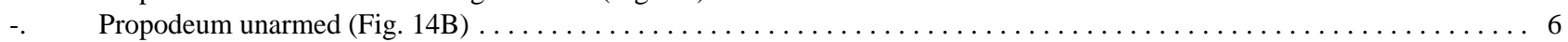

4. In dorsal view node of petiole much broader than long and rectangular in shape; body smaller (HW $<0.82 \mathrm{~mm})$ (Australia) . .

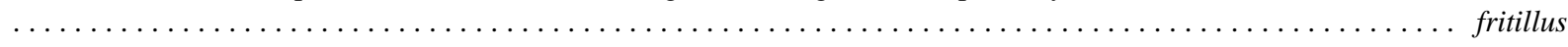
In dorsal view node of petiole only slightly broader than long and oval in shape; body larger $(\mathrm{HW}>1.00 \mathrm{~mm}) \ldots \ldots \ldots 5$

5. Body larger (HW > 1.12); head longer than broad (CI < 98); spatulate hairs on posterior section of head and mesonotum appressed closely to the underlying body surface; propodeal spines larger and more strongly angled (angle between faces

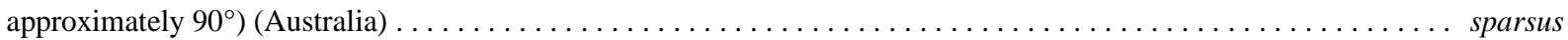
Body smaller (HW < 1.12); head broader than long (CI > 104); spatulate hairs on posterior section of head and mesonotum rising above the underlying body surface; propodeal spines shorter and broader (angle between faces greater than $90^{\circ}$ ) $($ Malaysia)

6. Hairs on head narrowly spatulate and rising well above the underlying body surface; in dorsal view node of petiole rectangular, in lateral view relatively thin; body smaller $(\mathrm{HW}<0.82 \mathrm{~mm})$ (Australia) $\ldots \ldots \ldots \ldots \ldots \ldots \ldots \ldots \ldots \ldots \ldots \ldots$ taylori Hairs on head broadly spatulate and appressed closely to the underlying body surface; in dorsal view node of petiole rounded,

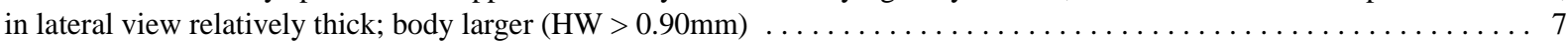

7. Posterior margin of head above the level of antennal scrobes broader, the lateral corners more angular; body larger (HW > $1.13 \mathrm{~mm}$ ); spatulate hairs broader and more rounded (Malaysia, Philippines) $\ldots \ldots \ldots \ldots \ldots \ldots \ldots \ldots \ldots$. $\ldots \ldots$ loryi Posterior margin of head above the level ov antennal scorbed narrower and the lateral corners more rounded; body smaller $(\mathrm{HW}<1.10 \mathrm{~mm})$; spatulate hairs narrower and more linear (widespread) $\ldots \ldots \ldots \ldots \ldots \ldots \ldots \ldots \ldots \ldots \ldots$ beccarii

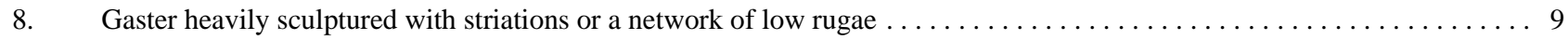

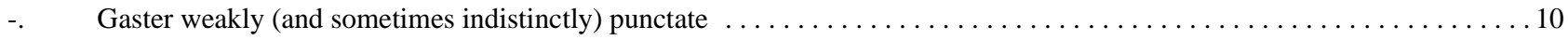

9. Sculpturing on gaster consisting of a network anteriorly and striations posteriorly, the individual rugae very closely spaced;

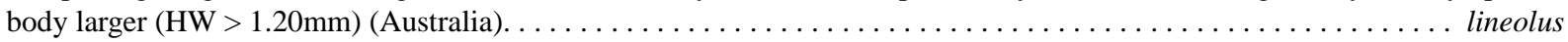
Sculpturing on gaster a series of widely spaced longitudinal striations; body smaller $(\mathrm{HW}<1.00 \mathrm{~mm})$ (Malaysia) $\ldots . . . .$.

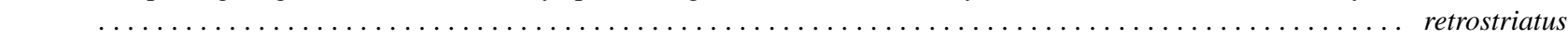

10. Propodeum lacking or essentially lacking spines or angles (although slightly convex rugae may be present near the angle)

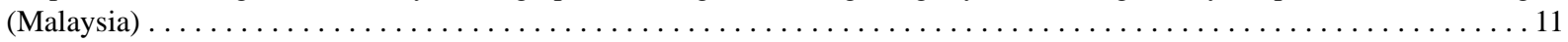

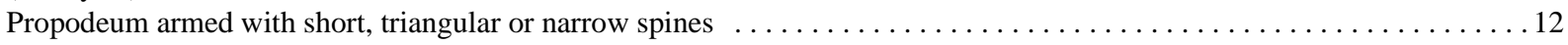

11. Lateral surfaces of mesosoma and dorsal surface of head with a limited number of well defined, broad rugae which are well separated; hairs on mesonotum relatively short and tending to be weakly spatulate; petiolar node in dorsal view only slightly

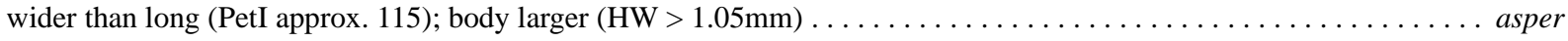
Lateral surfaces of mesosoma and dorsal surface of head with numerous narrow, ill-defined rugae which are more closely spaced; hairs on mesonotum relatively long and only slightly swollen distally; petiolar node in dorsal view noticeably wider

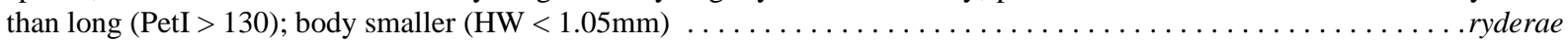

12. Setae on leading edge of scape long, about as long as scape width; propodeal spines broadly triangular; legs rugo-reticulate

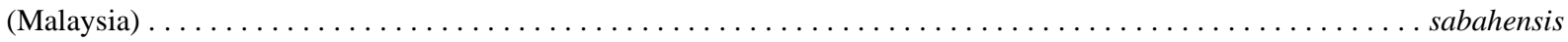
Setae on leading edge of scape short, shorter than scape width; propodeal spines narrower and more spine-like; legs punctate

13. Mesonotum and dorsal face of propodeum forming a single, continuous surface; petiolar node more upright and block-like, in

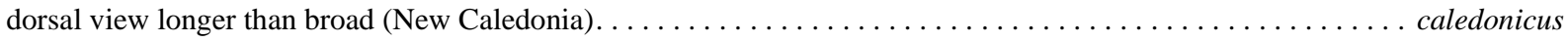
Mesonotum and dorsal face of propodeum separated by an angle; petiolar node leaning slightly posteriorly, the anterior face

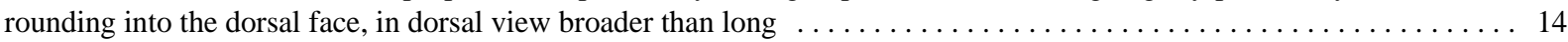

14. Rugae on dorsum of head widely spaced, the underlying punctate surface clearly visible, the rugae fading posteriorly and essentially absent near the posterior margin (Vietnam) $\ldots \ldots \ldots \ldots \ldots \ldots \ldots \ldots \ldots \ldots \ldots \ldots \ldots$ rectopilosus Rugae on dorsum of head closely spaced and largely obscuring the underlying surface, the rugae strongly developed across the

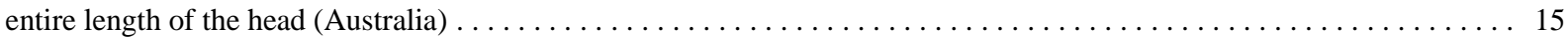

15. Mesonotum rugo-reticulate but with rugae running longitudinally; propodeal spines shorter; petiolar node in dorsal view

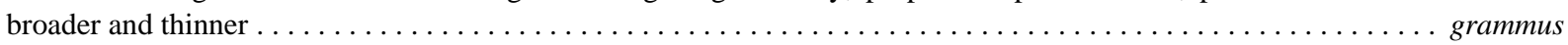
Mesonotum rugo-reticulate but lacking longitudinal rugae; propodeal spines longer; petiolar node in dorsal view narrower and

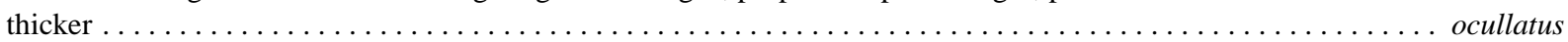




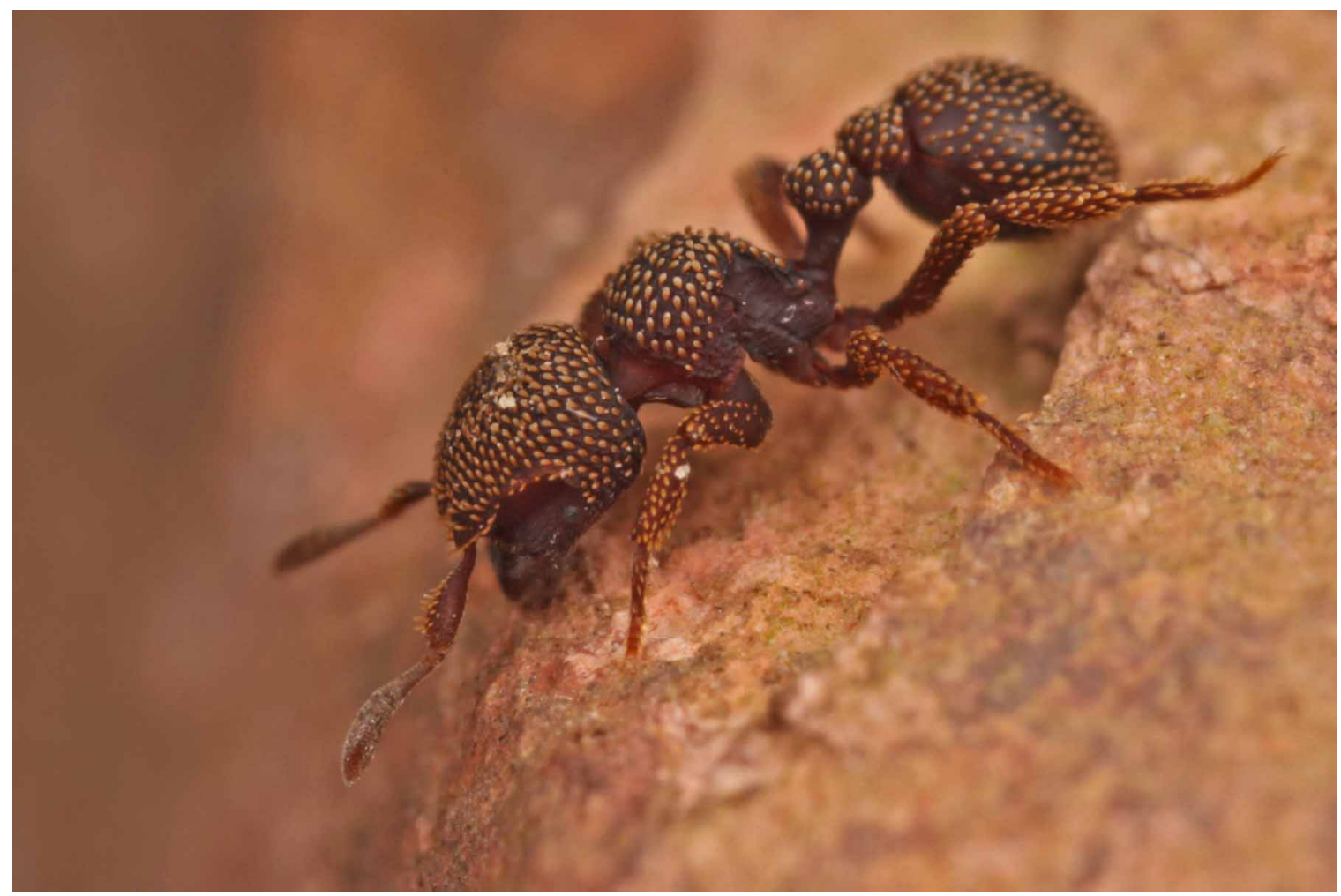

FIGURE 1. Calyptomyrmex loweryi worker (Danum Valley Field Centre, Sabah, Malaysia). The nest of this colony was in soil under a large log in primary rainforest.

\section{Calyptomyrmex asper sp. $\mathbf{n}$.}

(Figs 2, 18)

Types. Holotype worker from Nanga Tekalit Camp, Sarawak, Malaysia, 14 February 1963, A. E. Emerson (ANIC32-051667).

Diagnosis. Hairs on head and body thin (essentially the same width along entire length, or only slightly and gradually expanded distally, and with blunt tips), propodeum lacking spines, gaster weakly (and sometimes indistinctly) punctate, and body larger ( $\mathrm{HW}>1.05 \mathrm{~mm})$. This combination of characters will separate this species from all others considered in this study. For separation from the similar ryderae, see Diagnosis under that species.

Worker description. Lateral margins of head in full-face view relatively strongly diverging posteriad. Mandibles indistinctly striate, more strongly basally, less so apically. Eyes with 4-5 ommatidia in greatest diameter. Propodeum in lateral view lacking angles or spines (slight convexities are present on the propodeum in the vicinity of the angle, but these are extensions of the lateral propodeal rugae and are not true spines). Propodeal lobes thin anteriorly, thickened posteriorly. Node of petiole in profile higher and much larger than that of postpetiole, its anterior angle broadly rounded between the anterior and dorsal faces. In dorsal view the petiolar node slightly narrower than the postpetiolar node. Head, mesosoma, and petiolar and postpetiolar nodes with heavy, deep, wavy rugae, the entire surface (including the rugae) indistinctly sculptured and with a matte appearance. Gaster finely and indistinctly sculptured. Hairs on head and body erect and expanded slightly distally, their tips either blunt or slightly convex (but never rounded). Clypeal fork with both enlarged and thin hairs, the thin hairs longer. Colour dull redbrown, antennae and legs slightly lighter.

Measurements. Worker (holotype) - CFW 0.12; CI 105; HL 1.00; HW 1.06; ML 1.05; MTL 0.51; PetI 115; PetL 0.31; PetW 0.36; PronW 0.67; SI 55; SL 0.59.

Comments. This species is known from a single specimen. Nothing is known regarding its biology. 


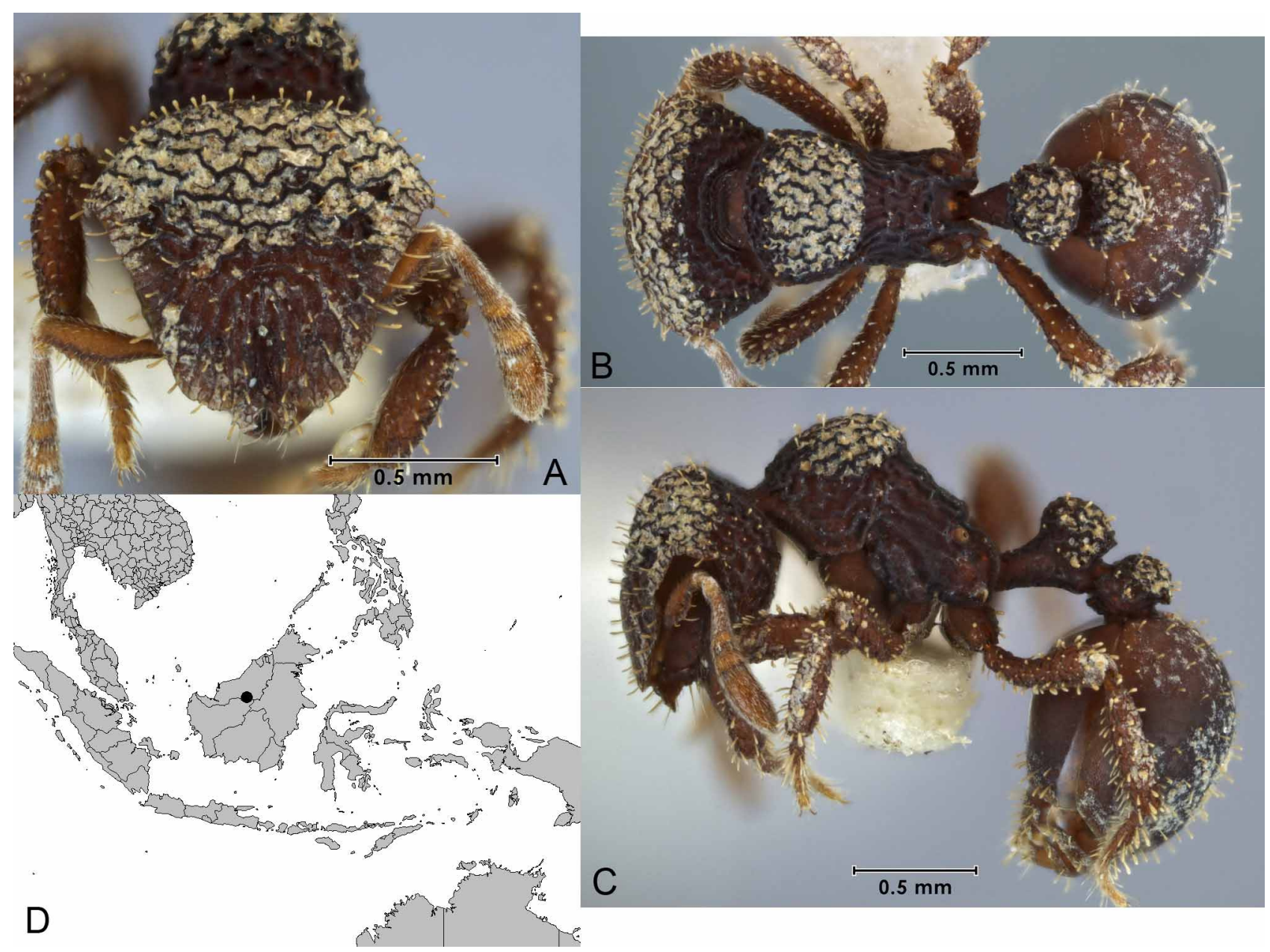

FIGURE 2. Calyptomyrmex asper (holotype, ANIC32-051667): A. Front of head; B. Side of body; C. Top of body; D. Distribution of material examined.

\section{Calyptomyrmex beccarii Emery}

(Figs 3, 18)

Calyptomyrmex beccarii Emery, 1887: 472.

Calyptomyrmex beccarii glabratus Viehmeyer, 1916: 128 (raised to species by Baroni Urbani, 1975: 410). New synonym. Calyptomyrmex emeryi Forel, 1901: 51 (queen described by Wheeler, 1919: 90). New synonym.

Calyptomyrmex schraderi Forel, 1901: 50 (neotype designation and junior synonym of C. beccarii by Taylor, 1991: 600). Weberidris rufobrunnea Donisthorpe, 1949a: 281 (combination in Calyptomyrmex by Donisthorpe, 1949b: 186 and Brown, 1949: 84; junior synonym of $C$. beccarii by Brown, 1951: 101).

Types. C. beccarii: Worker (apparently a single specimen, therefore holotype) from Ambon (as Amboina), Indonesia (MSNG, not examined). C. beccarii glabratus: Two worker syntypes from Singapore (MNHB, images from www.anttypes.org examined). C. emeryi: Three worker and one male syntype from Sarawak, Malaysia (MHNG, examined). C. schraderi: Neotype worker from Iron Range, Queensland, ANIC32-047446, designated by Taylor (1991) (ANIC, examined). W. rufobrunnea: Holotype worker from Maffin (as Maffin Bay), Papua, Indonesia (BMNH, not examined, specimens from type nest series present in MCZC, examined).

Diagnosis. Hairs on head and body spatulate (noticeably narrower near the body and expanded distally and with a rounded tip) and appressed closely to the underlying body surface, gaster finely and indistinctly sculptured, propodeum unarmed, posterior margin of head more rounded, especially its lateral corners. This species is most similar to loweryi but differs in having the head narrower above the level of the antennal scrobe and in being smaller ( $\mathrm{HW}<1.10 \mathrm{~mm}$ rather than greater than $1.13 \mathrm{~mm}$ ). 


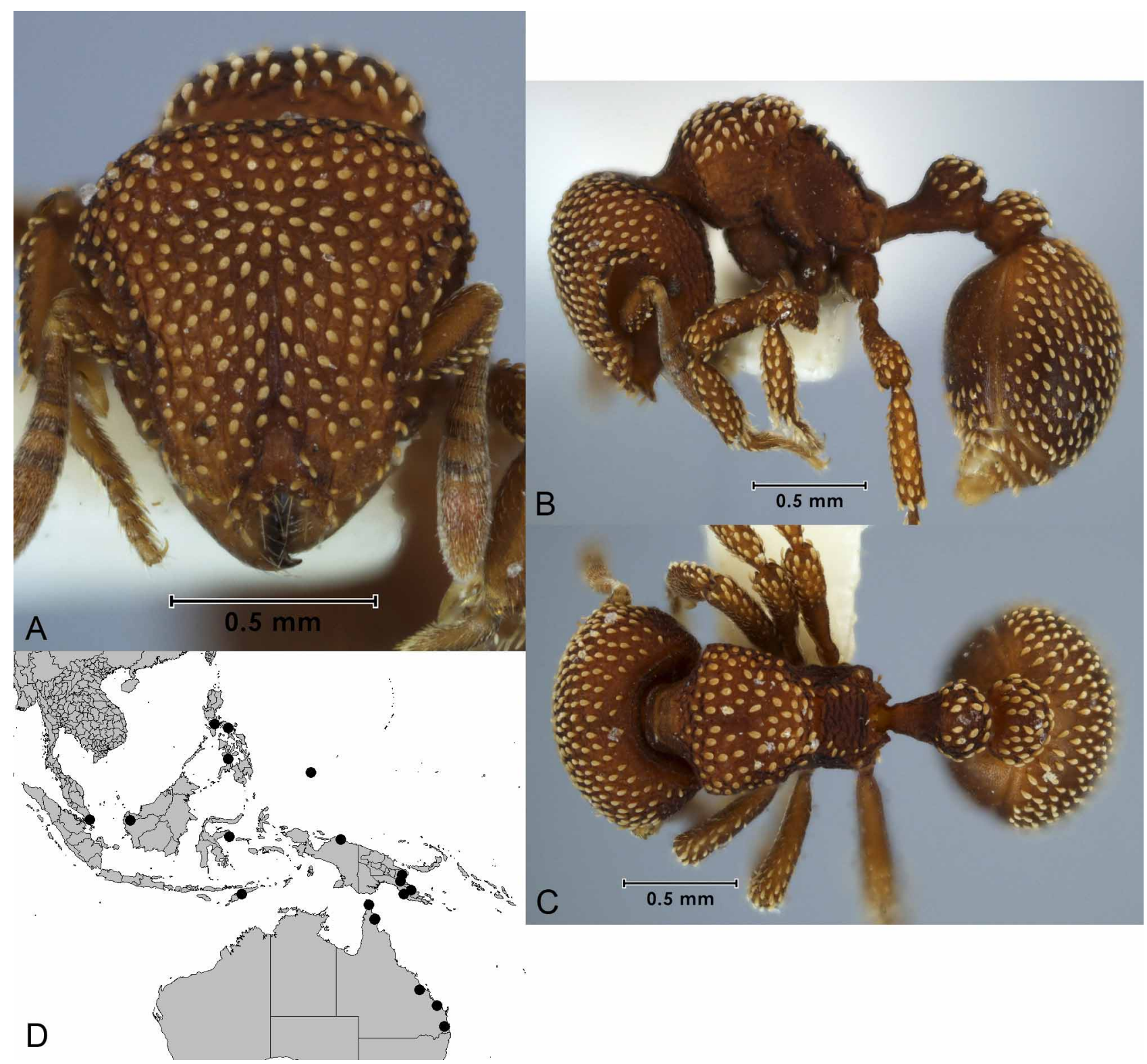

FIGURE 3. Calyptomyrmex beccarii (Iron Range, Queensland, ANIC32-047446): A. Front of head; B. Side of body; C. Top of body; D. Distribution of material examined.

Worker description. Mandibles delicately striate (sometimes weakly so). Eyes with 5-6 ommatidia in greatest diameter. Propodeum in lateral view lacking angles or spines. Propodeal lobes thin anteriorly, thickened posteriorly. Node of petiole in profile slightly higher and larger than that of postpetiole. In dorsal view the petiolar node slightly narrower than the postpetiolar node. Head, promesonotum, dorsal and posterior faces of propodeum and petiolar and postpetiolar nodes rugose, the rugae enclosing foveolate spaces, this sculpturing most strongly developed on the front of the head, weaker and less defined posteriorly. Sides of mesosoma irregularly rugose, more strongly on pronotum, weakly so on propodeum. Spaces between rugulae indistinctly shagreened or finely reticulate-punctulate, matt and dull. Gaster finely and indistinctly sculptured. Hairs on head and body spatulate and appressed. Clypeal fork with spatulate hairs only. Colour dull red-brown.

Measurements. Worker $(\mathrm{n}=11)$ - CFW 0.19-0.22; CI 97-105; HL 0.95-1.06; HW 0.93-1.09; ML 0.91-1.02; MTL 0.43-0.53; PetI 123-148; PetL 0.22-0.28; PetW 0.29-0.39; PronW 0.60-0.74; SI 50-54; SL 0.49-0.57.

Additional material examined (in ANIC except where noted). Australia: Queensland: $18.5 \mathrm{~km}$ W St. Lawrence (Cook \& Monteith) (QMBA); Boombana Nat. Park, Site 1 (QM Party) (QMBA); Iron Range (Taylor,R.W. \& Feehan,J.) (ANIC, QMBA, TERC); Lockerbie, Cape York (Monteith,G.B.); Mt Jacob, c.45mi. S Gladstone (Darlingtons) (MCZC). East Timor: Salele, 23km W Suai, Suai Kabupaten (Agosti,D.). Indonesia: Papua: Maffin Bay 
(Ross,E.S.) (MCZC); Central Sulawesi: Polit Kecil, Banggai Arch. (Brendell,M.J.D.) (BMNH). Malaysia: Sarawak: Kampong Segu, 20mi. SW Kuching (Taylor,R.W.). Palau Islands: Koror Island (Dybas,H.S.) (MCZC). Papua New Guinea: Central: 5-6km N Brown River, C.P. (Brown,W.L.) (MCZC); Karema, Brown River (Wislon,E.O.) (MCZC); East Sepik: Yawasora (collector unknown); Morobe: Lae (Woodward,T.E.); Mt. Mission, Wau (Cuccodoro,G.) (BMNH); Northern: Lejo (Room,P.M.); Popondetta (Room,P.M.); Togao Rd. (Room,P.M.). Philippines: Camarines Sur: Panicuason Village, 18km E Naga City (General,D. \& Alpert,G.) (MCZC); Luzon: Mt. Makiling, Lagunas (Löbl,I.) (BMNH); Negros Oriental: Camp, Dumaguete (Chapman,J.W.) (MCZC). Singapore (MNHB).

Comments. This is by far the most widespread species examined in this study, occurring from Singapore north-east to the Philippines and south to Papua New Guinea and northern Australia. And although it is not particularly morphologically variable, it has been described no fewer than five times. For example, Taylor (1991) recognised that schraderi was conspecific with beccarii and also speculated that glabrata might be a junior synomym as well, although he did not study this last problem in detail and left the taxonomic status of these taxa unchanged. These proposals, as well as the synonymy of emeryi, are supported in this study.

Taylor's (1991) synonymy of the Australian-based schraderi with beccarii is supported here. However, it should be noted that the Australian populations do show slight differences when compared to more northern populations. Specifically, the spatulate hairs on the head and mesosoma of northern populations are narrower and more slender compared to the broader and more rounded hairs found in Australian specimens. However, hairs on the gaster are essentially identical and no further differences were found. Thus the available evidence suggests that these differences are little more than population-based geographic variation.

Comparable differences are also present in the single specimen of this taxon from East Timor. While very similar to other specimens examined during this study, this specimen differs in having the spatulate hairs on the head and mesosoma more erect and raised distinctly above the surface of the body. In specimens from other regions these hairs are at most only slightly raised above the surface. As with Australian specimens, no other differences were detected and this specimen is here considered to belong to beccarii.

The types of glabratus, the western-most samples known for this species, show only slight differences from other specimens here placed in this taxon. These differences include the petiolar node in lateral view being slightly higher and more angular and the pronotal corners in dorsal view being more angular compared to specimens from further east. However, these differences are slight and are not unexpected for such a wide-spread species. Because no additional differences could be found glabratus is here considered to be a junior synonym of beccarii. This confirms the suspicions of Taylor (1991).

Finally, an examination of the holotype of emeryi shows this taxon conforms to the concept of beccarii developed here and is a straightforward synonym. Forel (1901) provided a very brief description and failed to note any differences between this species and either beccarii or schraderi (which he described in the same paper as emeryi). None could be found during this study and therefore this name is treated as conspecific with beccarii.

As with most other species within this genus, beccarii is found in rainforest and is most often encountered in leaf litter samples, although one nest was found in a carton termite nest.

\section{Calyptomyrmex caledonicus sp. $\mathbf{n}$.}

(Fig. 4)

Types. Holotype worker and 1 worker paratype from Foret de Thy, New Caledonia, 21 May 1984, G. Monteith \& D. Cook, rainforest, litter (holotype ANIC32-051668, paratype ANIC32-053399).

Diagnosis. Hairs on head and body thin (essentially the same width along entire length, or only slightly and gradually expanded distally, and with blunt tips), propodeum armed with short, triangular spines, mesonotum and dorsal face of propodeum forming a single, continuous surface (the mesonotum and propodeum uniformly curved). This is the only species from this region with a uniformly curved mesosomal dorsum.

Worker description. Mandibles delicately striate basally, essentially smooth apically. Eyes small, with 2-3 ommatidia in greatest diameter. Propodeum in lateral view armed with short, thin spines. Propodeal lobes essentially uniform in thickness. Node of petiole in profile cubic or box-like and higher than that of postpetiole, both approximately the same volume. In dorsal view the petiolar node narrower than the postpetiolar node. Head indis- 
tinctly rugose, the rugae tending to be longitudinal anteriorly and forming a weak network posteriorly, with the entire surface finely but distinctly punctate, the punctations partially obscuring individual rugae. Mesosoma and petiolar and postpetiolar nodes rugose superimposed over an indistinctly punctate background, the individual rugae wavy and sometimes forming a network, otherwise more or less linear. Gaster finely and indistinctly sculptured. Hairs erect, uniform in diameter or slightly swollen medially or distally, generally with sharply pointed tips. Clypeal fork with enlarged and thin hairs which are approximately the same length. Colour yellow-red, antennae and legs slightly lighter.

Measurements. Worker $(\mathrm{n}=12)$ - CFW 0.10-0.14; CI 88-94; HL 0.68-0.80; HW 0.62-0.76; ML 0.63-0.79; MTL 0.28-0.35; PetI 110-133; PetL 0.16-0.21; PetW 0.21-0.26; PronW 0.42-0.52; SI 57-65; SL 0.38-0.45.

Additional material examined (in ANIC except where noted). New Caledonia: $5 \mathrm{~km} \mathrm{~S}$ Gelima (Monteith,G.B.) (QMBA); Cap Ndoua (Monteith,G. \& Grimbacher,P.) (QMBA); Chapeau Gendarme (Yahoue) (Wilson,E.O.) (MCZC); Ciu, nr. Mt. Canala (Wilson,E.O.) (ANIC, MCZC); Col de Petchecara, N end (Monteith,G.) (QMBA); Foret de Thy (Monteith,G. \& Cook,D.) (ANIC); Hwy., 8km SW Pombey (Monteith,G.) (QMBA); Mt. Do, Gate (Ward,P.S.) (QMBA); Thi Riviere Forestry Post (Ward,P.S.); Umg, Tindou bei Hyenghene (Franz,H.); Yahoe, 12km N Noumea (Kuschel,G.); Yahoue (Monteith,G.B.) (QMBA).

Comments. This is the only species of Calyptomyrmex known from New Caledonia. Morphologically, the available material is fairly uniform although it does show moderate variation in size. However, this size variation is continuous with no indication of distinct subsets and it is here interpreted as intraspecific.

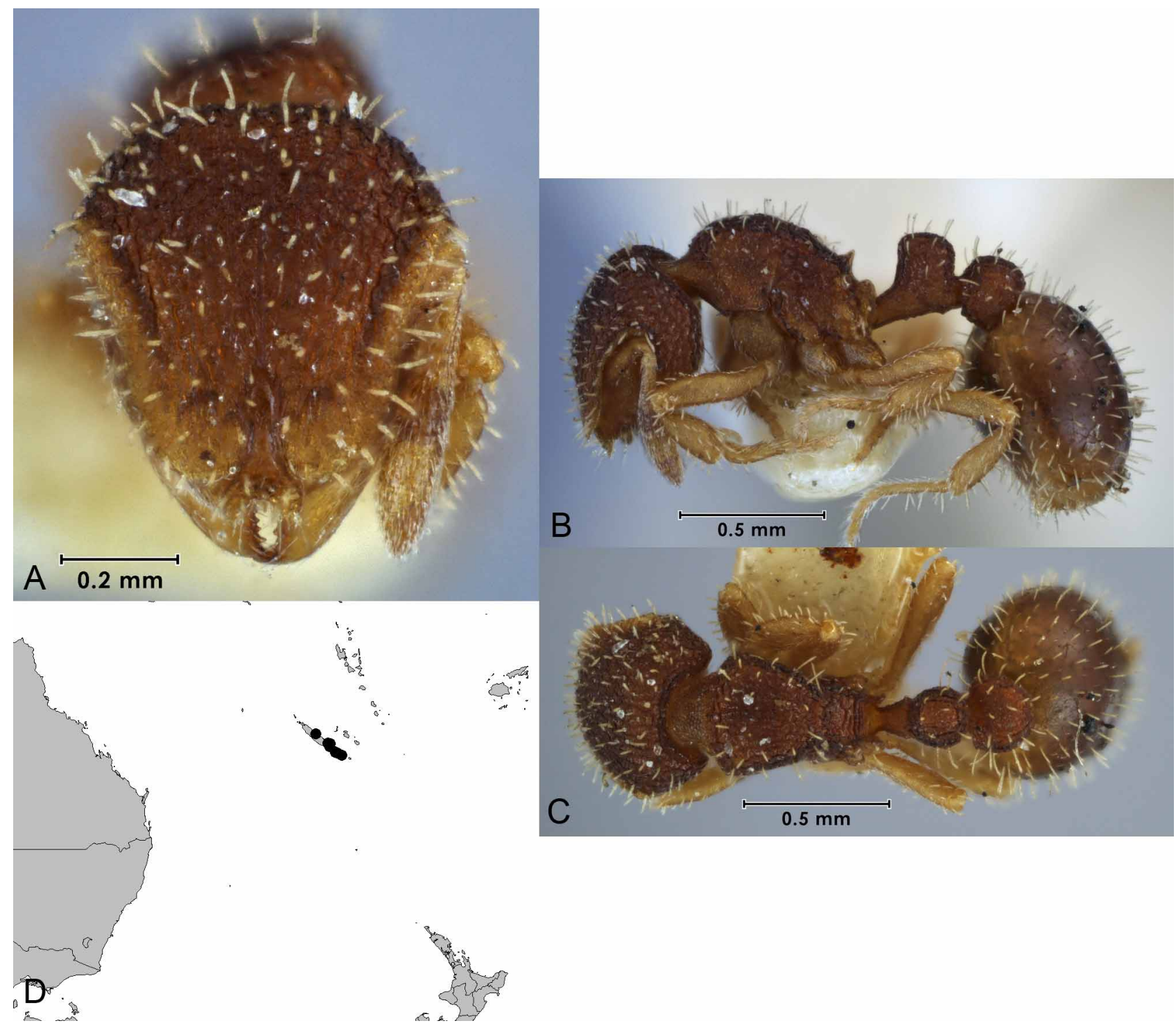

FIGURE 4. Calyptomyrmex caledonicus (Ciu, nr. Mt. Canala, New Calendonia, ANIC32-051669): A. Front of head; B. Side of body; C. Top of body; D. Distribution of material examined. 


\section{Calyptomyrmex danum sp. $\mathrm{n}$.}

(Figs 5, 18)

Types. Holotype worker and 10 worker and 1 queen paratype from Danum Valley, Sabah, Malaysia, M. Ellwood (holotype and 2 worker paratypes collected 17 November 1999, queen collected 19 October 1999 (BMNH), 8 worker paratypes collected 13 July 1999 (ANIC, BMNH)).

Diagnosis. Hairs on head and body spatulate (noticeably narrower near the body and expanded distally and with a rounded tip), gaster smooth to shallowly punctate, propodeum armed with short angular teeth and in dorsal view petiole only slightly broader than long and oval in shape. These characters will separate this species from all other known species except the Australian sparsus. It can be separated from this species in being smaller (HW < 1.12 vs. HW > 1.12), having the head broader than long (CI > 104 vs. CI < 98), with the spatulate hairs on the posterior section of head and mesonotum rising above the underlying body surface (they are closely appressed to the surface in sparsus) and in having the propodeal spines shorter and broader (angle between faces greater than $90^{\circ}$ ) while they are larger and more strongly angled (angle between faces approximately $90^{\circ}$ ) in sparsus. Additionally, the sculpturing on the head and body are more weakly developed with the rugae relatively shallow compared to that found in sparsus.

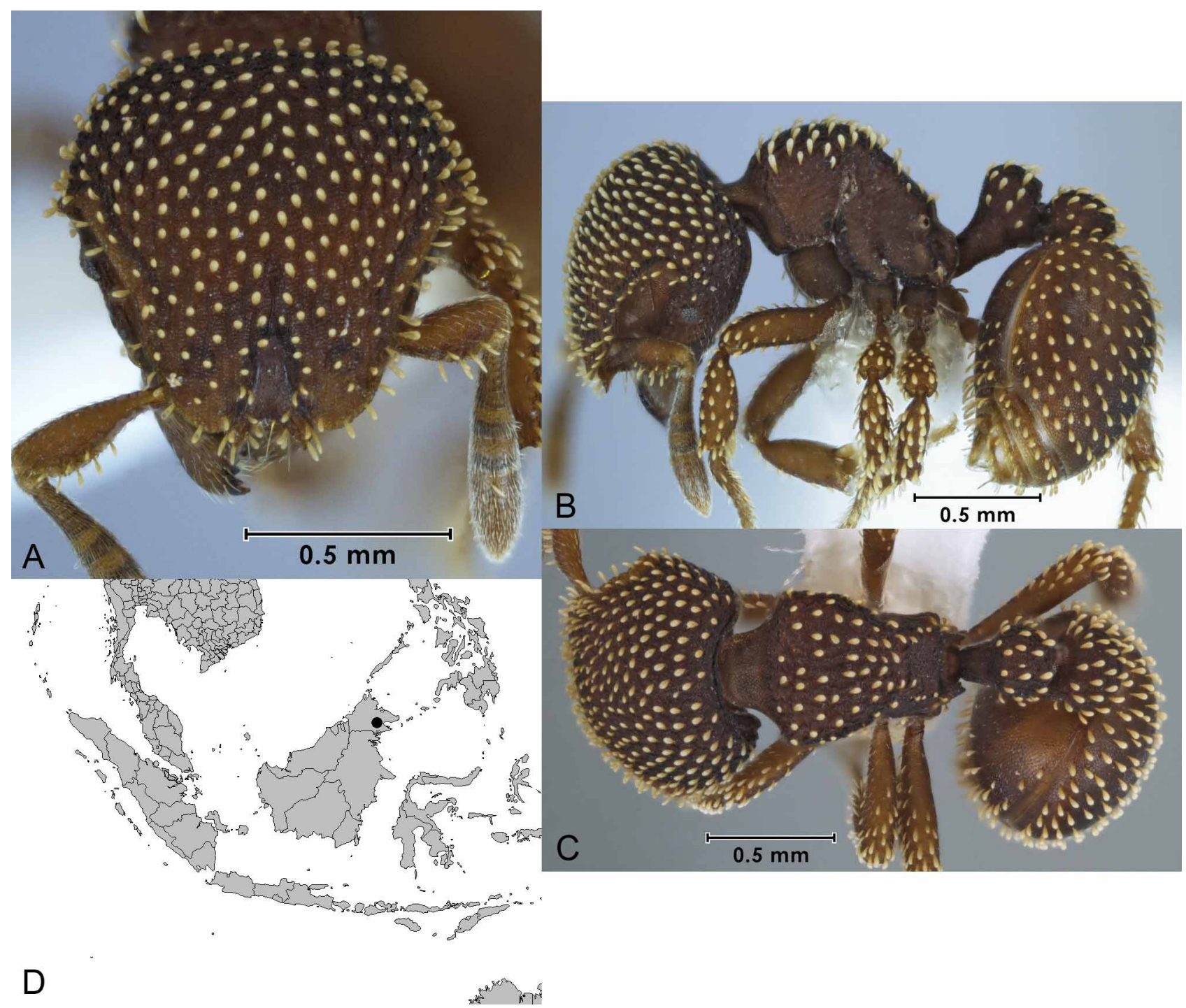

FIGURE 5. Calyptomyrmex danum (holotype): A. Front of head; B. Side of body; C. Top of body; D. Distribution of material examined. 
Worker description. Mandibles indistinctly striate, more strongly basally, less so apically. Eyes with 6-7 ommatidia in greatest diameter. Propodeum in lateral view with short, broadly angular teeth. Propodeal lobes uniform in thickness. Node of petiole in profile slightly higher than and approximately the same thickness as the postpetiole. In dorsal view the petiolar node narrower than postpetiolar node. Head, promesonotum and petiolar and postpetiolar nodes irregularly rugose, the rugae enclosing foveolate spaces, the rugae less well developed on the postpetiole. Sides of mesosoma irregularly rugose, more strongly on pronotum, weakly so on propodeum. Spaces between rugulae indistinctly shagreened or finely reticulate-punctulate, matt and dull. Gaster finely and indistinctly sculptured, moderately shiny. Hairs on head and body spatulate and appressed. Clypeal fork hairs thickened, the medial hairs thinner and less spatulate than the lateral hairs. Colour dull red-brown.

Measurements. Worker $(n=4)$ - CFW 0.17-0.19; CI 106-108: HL 0.95-1.04; HW 1.02-1.10; ML 0.91-1.02; MTL 0.44-0.51; PetI 124-137; PetL 0.24-0.27; PetW 0.30-0.36; PronW 0.62-0.74; SI 51; SL 0.52-0.56.

Comments. This species has been collected several times at a single rainforest site in eastern Sabah.

\section{Calyptomyrmex fragarus sp. $\mathbf{n}$.}

(Fig. 6)

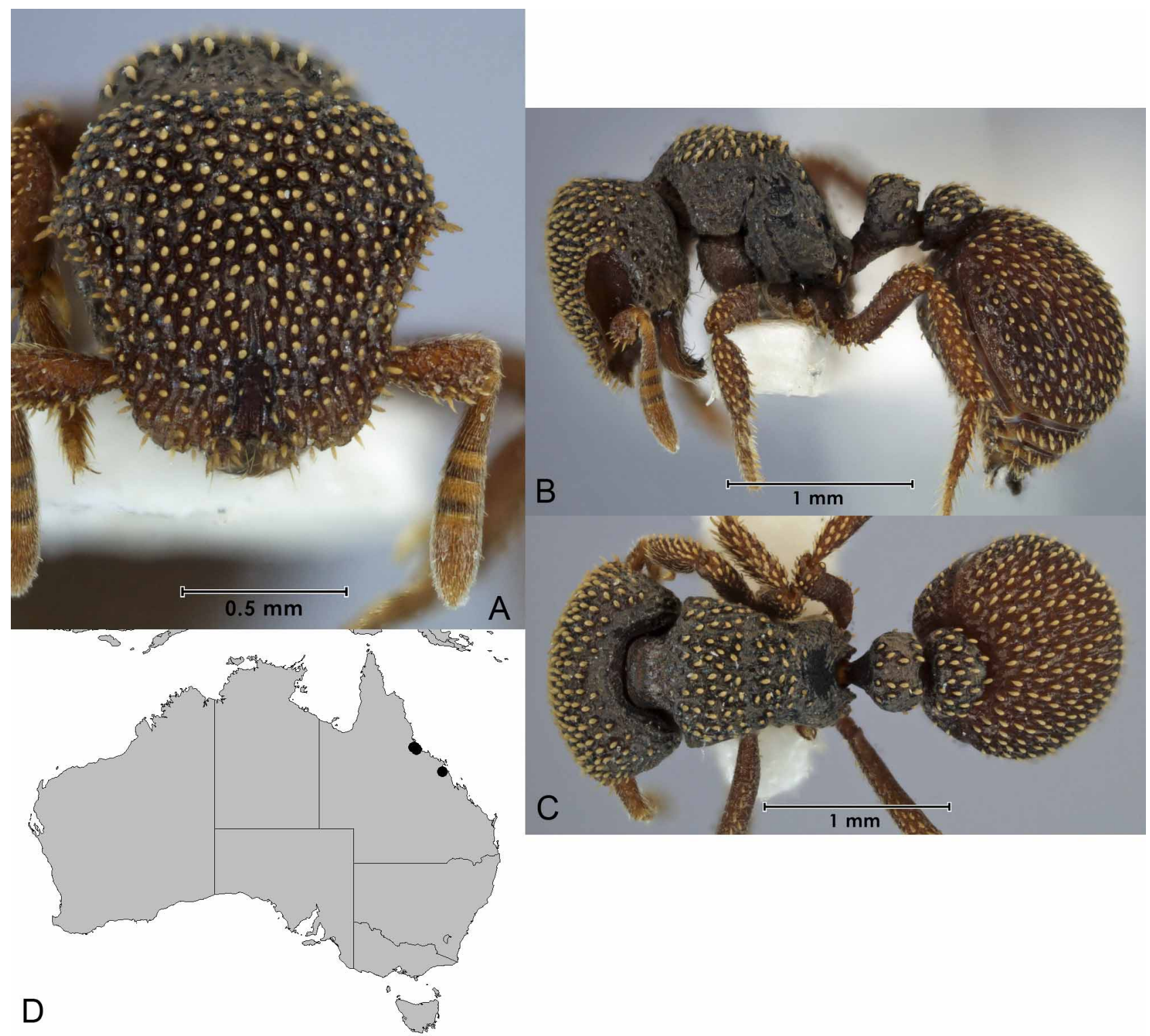

FIGURE 6. Calyptomyrmex fragarus (holotype, ANIC32-047443): A. Front of head; B. Side of body; C. Top of body; D. Distribution of material examined. 
Types. Holotype worker from 5km E Paluma \& 1 km below Crest, Queensland, 19 January 1970, J. G. Brooks, leaf litter (ANIC32-047443). Paratypes: 1 worker from 2km W Paluma, Paluma Range, Queensland, 7 May 1969, R. W. Taylor, rainforest, ground strays (ANIC32-047442); 1 worker from Bluewater Range, 45km NW Townsville, Queensland, 7 December 1986-16 February 1987, Monteith, Thompson \& Hamlet, rainforest (ANIC32-047445); 1 worker from Bluewater Range (Nth End), Queensland, 8 December 1986, G. Monteith \& G. Thompson, rainforest, sieved litter, (ANIC32-047444); 1 worker from Mt. Spec, Queensland, 8 May-5 June 1995, M. Cermak (ANIC32047440).

Diagnosis. Hairs on head and body spatulate (noticeably narrower near the body and expanded distally and with a rounded tip) and gaster with low longitudinal striations running between the spatulate hairs. This species shares the longitudinal striations on the gaster with lineolus but differs in having spatulate rather than thin hairs.

Worker description. Mandibles indistinctly striate, more strongly basally, less so apically. Eyes with 5-6 ommatidia in greatest diameter. Propodeum in lateral view lacking angles or spines. Propodeal lobes nearly uniform in thickness, only slightly thinner anteriorly than posteriorly. Node of petiole in profile slightly higher than that of postpetiole, both nodes approximately the same volume. In dorsal view the petiolar node slightly narrower than the postpetiolar node. Head, promesonotum and petiolar and postpetiolar nodes indistinctly foveolate, superimposed with punctations which disturb and partially obscure the surface. Sides of mesosoma irregularly rugose over fine but distinct punctations. Dorsum of propodeum very finely sculptured and with several longitudinal rugae. Gaster indistinctly foveolate anteriorly fading into striate posteriorly, the entire surface superimposed with punctations. Hairs on head and body spatulate and appressed. Clypeal fork with spatulate hairs only. Colour dull red-brown, the legs and sometimes the gaster slightly lighter.

Measurements. Worker ( $\mathrm{n}=6)$ - CFW 0.24-0.28; CI 102-109; HL 1.17-1.24; HW 1.23-1.31; ML 1.18-1.33; MTL 0.54-0.62; PetI 153-166; PetL 0.27-0.29; PetW 0.44-0.49; PronW 0.84-0.93; SI 49-53; SL 0.63-0.67.

Additional material examined. Australia: Queensland: Finch Hatton Gorge (Gillison,A.) (ANIC).

Comments. This uncommon Australian species has been collected in rainforest and mesophyll notophyll vine forest from both leaf litter samples and as stray ground foragers.

\section{Calyptomyrmex fritillus sp. $\mathbf{n}$.}

(Figs 7, 18)

Types. Holotype worker from Mt. Webb National Park, Queensland, 27-30 April 1981, A. Calder \& J. Feehan, rainforest, litter (ANIC32-053398). Paratypes: 4 workers, same data as holotype except ANIC32-051612 (2 in ANIC, 1 in BMNH, 1 in MCZC); 1 worker, same data as holotype except ANIC32-051613; 1 worker, same data as holotype except ANIC32-051614; 2 worker, same data as holotype except ANIC32-051615; 1 worker, same data as holotype except ANIC32-051616.

Diagnosis. Hairs on head and body spatulate (noticeably narrower near the body and expanded distally and with a rounded tip), gaster shallowly punctate, propodeum armed with short spines, in dorsal view petiole much broader than long and rectangular in shape and body smaller. This species is most similar to danum and sparsus but differs in having a smaller body $(\mathrm{HW}<0.90 \mathrm{~mm})$ and in dorsal view the petiole being much broader than long and rectangular in shape (in danum and sparsus the body is larger (HW $>1.0 \mathrm{~mm})$ and in dorsal view the petiole is only slightly broader than long and is oval in shape).

Worker description. Mandibles striate, more strongly basally, less so apically. Eyes with 3-4 ommatidia in greatest diameter, the individual facets ill-defined. Propodeum in lateral view armed with short spines. Propodeal lobes thin anteriorly, thickened posteriorly. Node of petiole in profile slightly higher and larger than that of postpetiole. Peduncle of petiole in lateral view relatively long and slender. In dorsal view the petiolar node slightly narrower than postpetiolar node. Head with weak longitudinal rugae anteriorly becoming net-like posteriorly where they form weakly defined foveolate spaces, the underlying surface punctate. Promesonotum and sides of mesosoma indistinctly rugo-reticulate, the dorsum more strongly sculptured than the sides, dorsum of propodeum with lateral rugae, entire mesosoma with a punctate background. Petiole, postpetiole and gaster punctate, the strength of the sculpture on the gaster fading slightly posteriorly. Hairs on head and body narrowly spatulate and raised above the surface of the body. Clypeal fork with enlarged, short and thin, elongate hairs. Colour yellow-red to red-brown. 
Measurements. Worker $(\mathrm{n}=7)$ - CFW 0.10-0.14; CI 94-97; HL 0.77-0.83; HW 0.72-0.80; ML 0.67-0.83; MTL 0.32-0.39; PetI 144-179; PetL 0.15-0.19; PetW 0.25-0.29; PronW 0.48-0.53; SI 57-62; SL 0.41-0.48.

Additional material examined (ANIC). Australia: Queensland: Gap Creek, 5km ESE Mt. Finnigan, near Cooktown (Calder,A. \& Feehan,J.), Mt. Cook National Park (Calder,A. \& Feehan,J.); Mt. Webb National Park (Calder,A. \& Feehan,J.).

Comments. Calyptomyrmex fritillus is known from a restricted region of Far North Queensland where it has been found in leaf litter samples from rainforest.

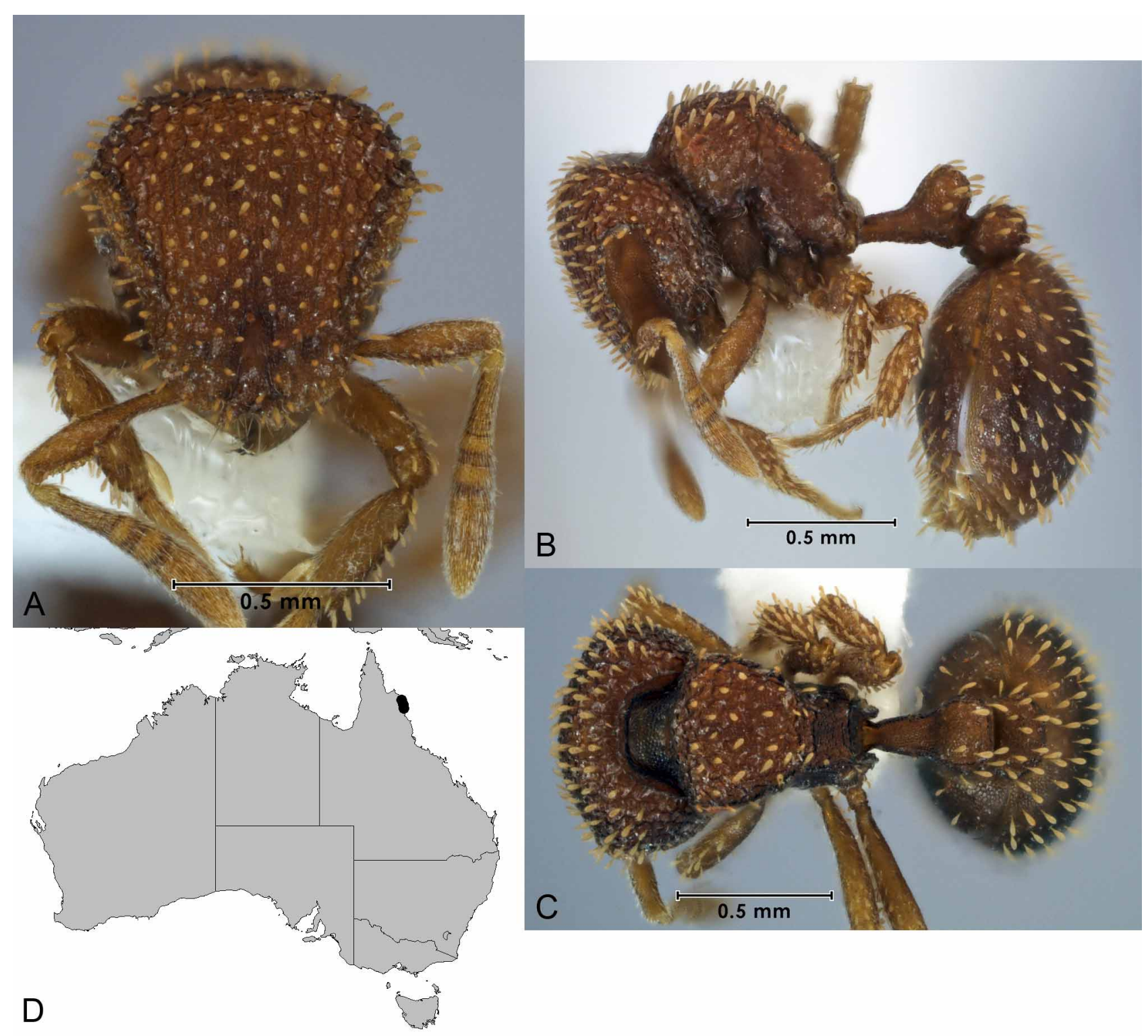

FIGURE 7. Calyptomyrmex fritillus (paratype, ANIC32-051612): A. Front of head; B. Side of body; C. Top of body; D. Distribution of material examined.

\section{Calyptomyrmex grammus sp. $\mathbf{n}$.}

(Fig. 8)

Types. Holotype worker and 8 paratype workers from Mulgrave River Road, 7km WbyS Bellenden Ker, Queensland, 2 April 1984, A. Calder \& T. Weir, rainforest (holotype ANIC32-053400, paratypes ANIC32-047438 (4 in ANIC, 2 in BMNH, 2 in MCZC)).

Diagnosis. Hairs on head and body thin (essentially the same width along entire length, or only slightly and gradually expanded distally, and with blunt tips), propodeum armed with short spines, gaster weakly punctate, 
mesonotum rugo-reticulate, the rugae running longitudinally, petiolar node relatively broad and thin in dorsal view. This species is most similar to ocullatus but can be separated from it by the presence of longitudinal rugae on the mesonotum (these are absent in ocullatus) and the petiolar node being relatively broad and thin in dorsal view (it is narrower and thicker in ocullatus).

Worker description. Mandibles delicately striate basally, essentially smooth apically. Eyes small, with 3-4 ommatidia in greatest diameter. Propodeum in lateral view armed with short, broad spines. Propodeal lobes slightly thickened posteriorly. Node of petiole in profile slightly higher than that of postpetiole, both approximately the same volume. In dorsal view the petiolar node similar in width or slightly broader than the postpetiolar node. Head indistinctly rugose, the rugae tending to be longitudinal anteriorly and forming a weak network posteriorly, with the entire surface finely but distinctly punctate, the punctations partially obscuring individual rugae. Mesosoma and petiolar and postpetiolar nodes rugose superimposed over an indistinctly punctate background, the individual rugae wavy and sometimes forming a network, otherwise more or less linear. Gaster finely and indistinctly sculptured, stronger anteriorly and fading slightly posteriorly. Hairs on head and body erect, uniform in diameter or narrowing slightly towards the base, generally with sharply pointed tips. Clypeal fork with enlarged and thin hairs, the thin hairs slightly longer. Colour red-brown, antennae and legs slightly lighter.

Measurements. Worker ( $\mathrm{n}=5$ ) - CFW 0.10-0.11; CI 94-98; HL 0.71-0.75; HW 0.70-0.73; ML 0.67-0.71; MTL 0.29-0.33; PetI 175-199; PetL 0.15-0.18; PetW 0.30-0.32; PronW 0.50-0.52; SI 58-61; SL 0.41-0.43.

Additional material examined. Australia: Queensland: Graham Range (Monteith,G.) (ANIC).

Comments. This species has only been encountered a handful of times. It is restricted to Far North Queensland rainforest where it has been collected from leaf litter samples.

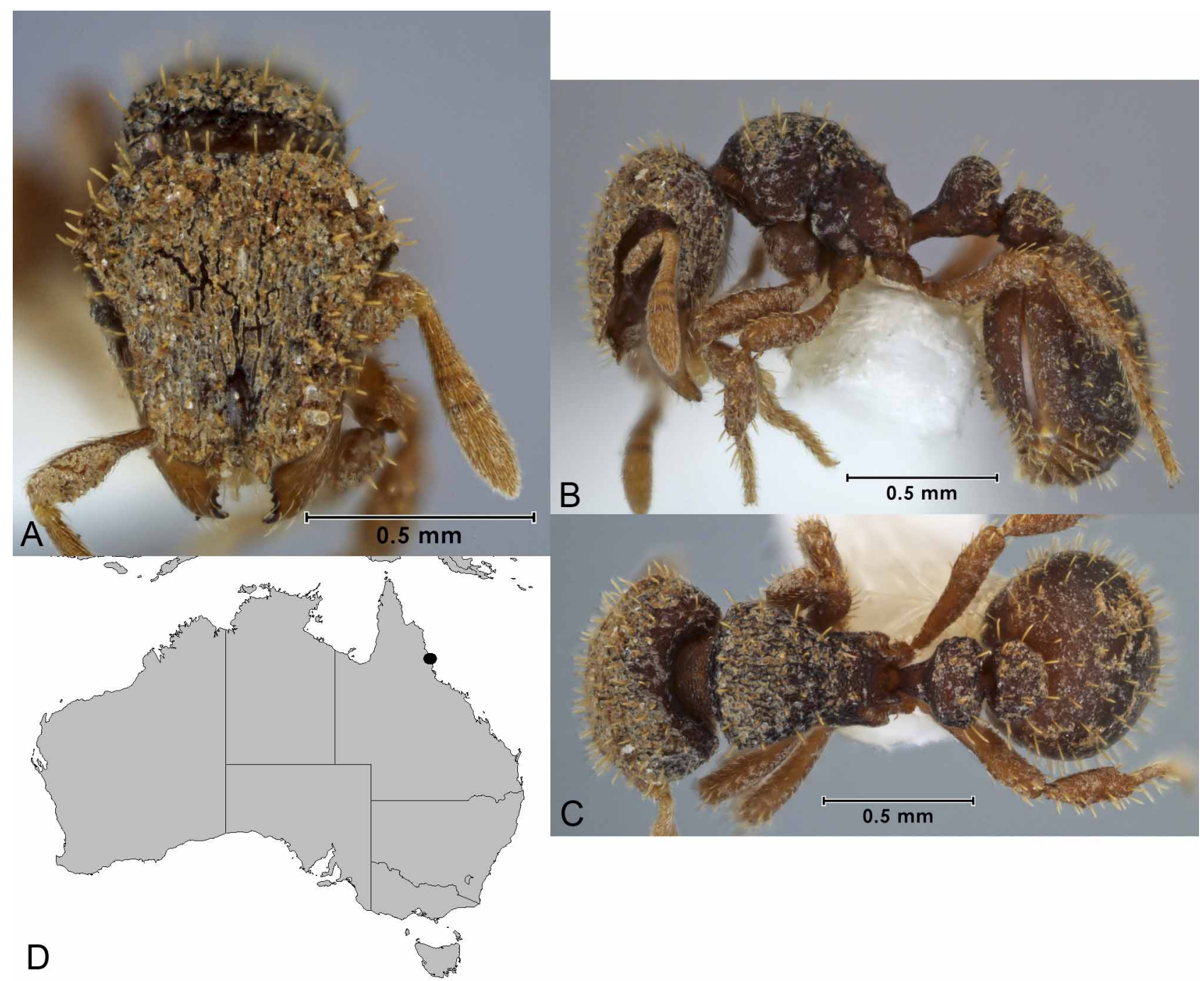

FIGURE 8. Calyptomyrmex grammus (holotype, ANIC32-047438): A. Front of head; B. Side of body; C. Top of body; D. Distribution of material examined. 


\section{Calyptomyrmex lineolus sp. $\mathbf{n}$.}

(Fig. 9)

Types. Holotype worker from Cannon Vale, Queensland, 25 April 1979, G. Monteith, dry rainforest (ANIC32047439).

Diagnosis. Hairs on head and body thin (essentially the same width along entire length, or only slightly and gradually expanded distally, and with blunt tips), propodeum lacking spines and gaster with low longitudinal striations. This species shares the longitudinal striations on the gaster with fragarus and retrostriatus but differs from fragarus in having thin rather than spatulate hairs and from retrostriatus in being larger (HW $>1.20 \mathrm{~mm}$ vs. HW < $1.00 \mathrm{~mm}$ in retrostriatus.

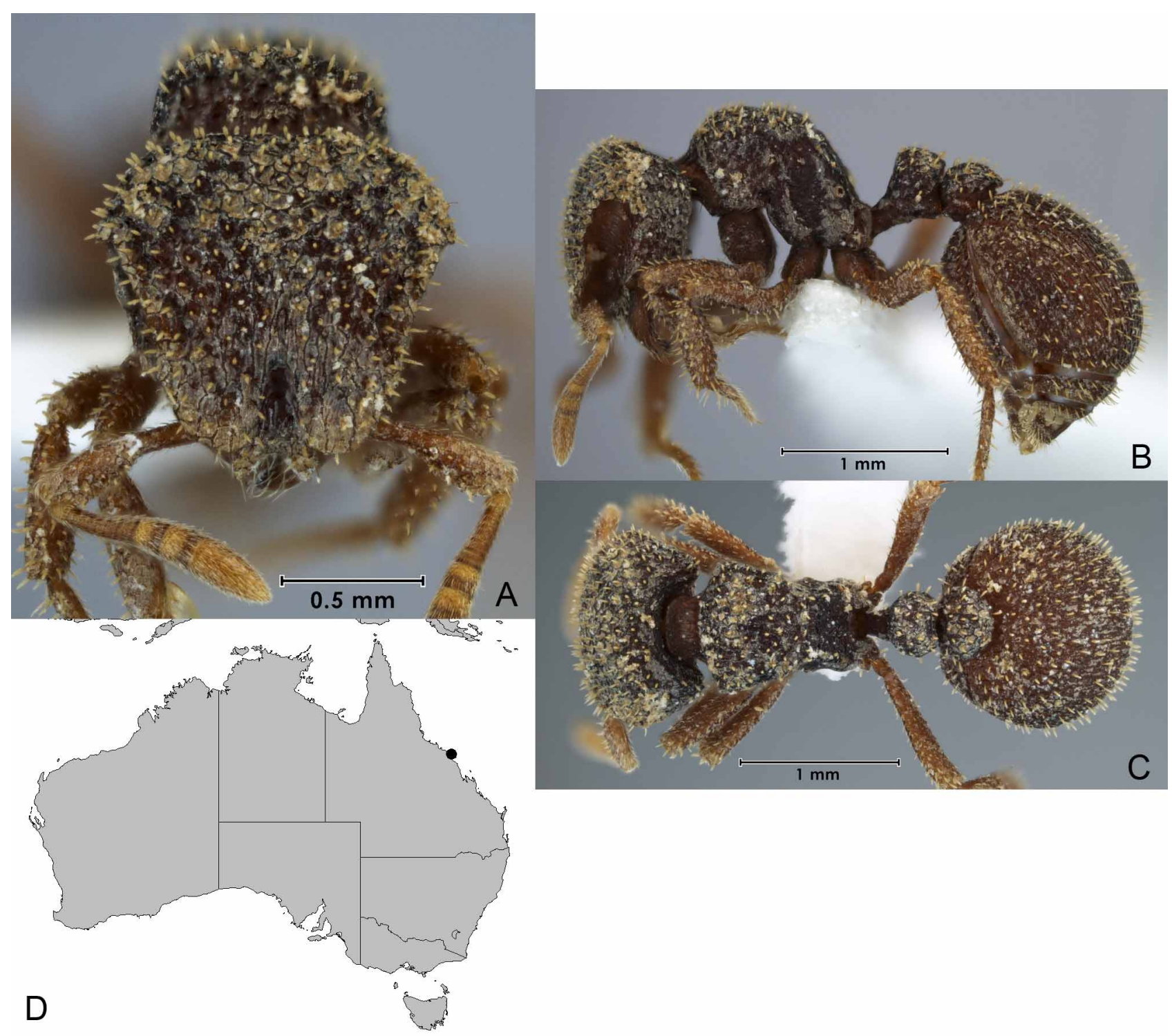

FIGURE 9. Calyptomyrmex lineolus (holotype, ANIC32-047439): A. Front of head; B. Side of body; C. Top of body; D. Distribution of material examined.

Worker description. Mandibles striate basally, essentially smooth apically. Eyes with 4 ommatidia in greatest diameter. Propodeum in lateral view lacking angles or spines. Propodeal lobes thin anteriorly, thickened posteriorly. Node of petiole in profile slightly higher than that of postpetiole, both approximately the same volume. In dorsal view the petiolar node slightly narrower than the postpetiolar node. Head rugose anteriorly and foveolate posteriorly, with spaces between rugulae indistinctly shagreened or finely reticulate-punctulate. Mesonotum longitudinally rugose, superimposed over indistinct shagreening. Side of mesosoma a matrix of large circular fovae-like pits and short longitudinal rugae, the entire surface superimposed with indistinct punctations. Dorsum of petiolar 
and postpetiolar nodes foveolate. Gaster foveolate anteriorly fading to longitudinally rugose posteriorly, the underlying surface indistinctly and irregularly punctate. Hairs on head and body erect, uniform in diameter with most narrowing slightly towards the base, and most on the mesosoma slightly swollen medially; generally with sharply pointed tips. Clypeal fork with slightly enlarged and thin hairs, all hairs approximately the same length. Colour redbrown, antennae and legs slightly lighter.

Measurements. Worker (holotype) - CFW 0.25; CI 103; HL 1.24; HW 1.28; ML 1.22; MTL 0.59; PetI 144; PetL 0.30; PetW 0.44; PronW 0.86; SI 58; SL 0.74.

Comments. This species is only known from a single collection made in dry rainforest.

\section{Calyptomyrmex loweryi sp. n.}

(Figs 10,18)

Types. Holotype worker, 108 worker paratypes and numerous larvae from $2 \mathrm{~km}$ N Malaybalay, Bukidnon, Philippines, 13 September 1978, B. B. Lowery, reafforestation area, in rotten log (holotype ANIC32-053401, paratypes ANIC32-051639 (102 in ANIC, 3 in BMNH, 3 in MCZC)). Paratypes: 2 workers, same data as holotype except ANIC32-051640; 112 workers and numerous larvae from 7km S Malaybalay, Bukidnon, Philippines, 8 September 1978, B. B. Lowery, rubber plantation, under large log (ANIC32-051641).

Diagnosis. Hairs on head and body spatulate (noticeably narrower near the body and expanded distally and with a rounded tip) and appressed closely to the underlying body surface, gaster finely and indistinctly sculptured, moderately shiny to moderately dull, propodeum unarmed, posterior margin of head flatter, its lateral corners more sharply rounded. This species is most similar to beccarii but differs in having the head broader and more angular above the level of the antennal scrobe and in being larger (HW $>1.13 \mathrm{~mm})$.

Worker description. Mandibles indistinctly striate, more strongly basally, less so apically. Eyes with 5-7 ommatidia in greatest diameter. Propodeum in lateral view lacking angles or spines. Propodeal lobes thin anteriorly, thickened posteriorly. Node of petiole in profile slightly higher and larger than that of postpetiole. In dorsal view the petiolar and postpetiolar nodes approximately the same width. Head, promesonotum and petiolar and postpetiolar nodes rugose, the rugae enclosing foveolate spaces, the spaces smallest on the head and larger on mesosoma and nodes. Sides of mesosoma irregularly rugose, more strongly on pronotum, weakly so on propodeum. Spaces between rugulae indistinctly shagreened or finely reticulate-punctulate, matt and dull. Dorsum of propodeum very finely sculptured and with a matte surface, a few very fine rugae sometimes present. Gaster finely and indistinctly sculptured, moderately shiny to moderately dull. Hairs on head and body spatulate and appressed. Clypeal fork with spatulate hairs only. Colour dull red-brown.

Measurements. Worker ( $\mathrm{n}=5$ ) - CFW 0.21-0.24; CI 104-108; HL 1.07-1.16; HW 1.15-1.25; ML 1.05-1.14; MTL 0.54-0.59; PetI 133-143; PetL 0.28-0.32; PetW 0.39-0.44; PronW 0.75-0.82; SI 48-51; SL 0.58-0.64.

Additional material examined. Malaysia: Sabah: Danum Valley Field Centre (Shattuck,S.O.) (ANIC); Poring Hot Springs (Burckhardt \& Löbl,I.) (BMNH); Gn. Silam (Leakey,R.) (BMNH); Sarawak: Gn. Mulu Natl Pk (Hammond,P.M. \& Marshall,J.E.) (BMNH); G. Mulu Natl Pk, RGS. Expd. Long Pala (Bolton,B.) (BMNH); Marudi (Hammond,P.) (BMNH); Santubong, 32km N Kuching (Löbl \& Burckhardt) (BMNH). Philippines: Luzon: Mt. Banahaw, Langunas (Löbl,I.) (BMNH); Mindanao: Bukidnon: 2km N Malaybalay (Lowery,B.B.) (ANIC); 7km S Malaybalay (Lowery,B.B.) (ANIC).

Comments. Taylor (1991) noted that the specimens from Malaybalay here placed in loweryi, together with others from Sarawak (which are here treated as belonging to beccarii), were similar to beccarii and might belong to that species or possibly to glabratus (which he speculated might actually be a synonym of beccarii, a treatment confirmed here). In fact, these Philippine specimens belong to a separate species (loweryi). Calyptomyrmex loweryi can be separated from beccarii as follows: (1) spatulate hairs broader than those found in beccarii, and less dense, especially on gaster; (2) posterior margin of head flatter and with the lateral corners more sharply rounded; (3) dorsal face of propodeum finely matte, lacking the low rugae found in beccarii; and (4) body larger (HW >1.13mm vs. HW $<1.10 \mathrm{~mm}, \mathrm{ML}>1.04 \mathrm{~mm}$ vs. ML $<1.03 \mathrm{~mm}$ ). Combined, these characters separate this species from close relatives.

Biologically, this species has been encountered in a rubber plantation, a reafforestation area and in rainforest, and were found in a rotten log, under a large log and in leaf litter samples. 


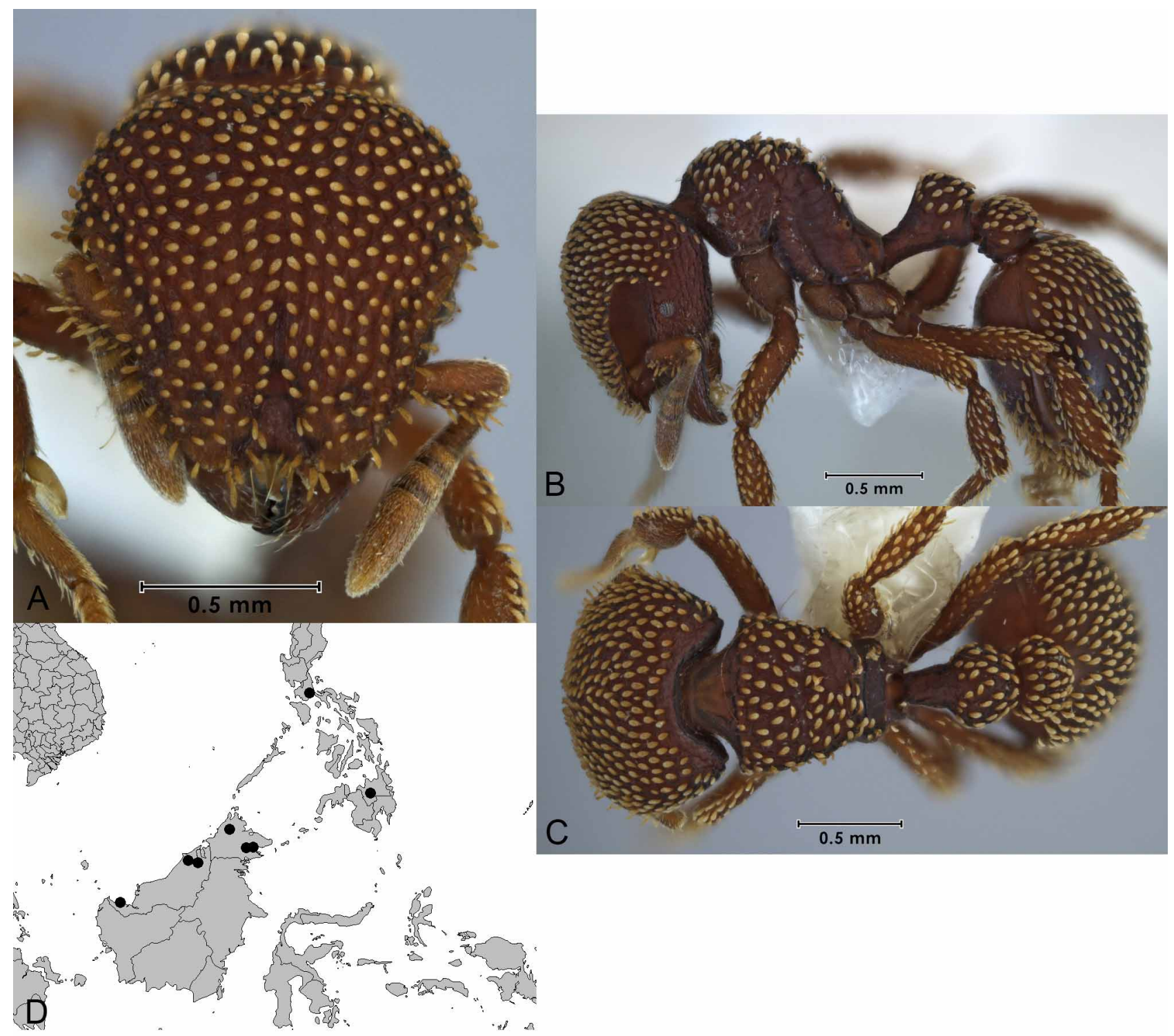

FIGURE 10. Calyptomyrmex loweryi (paratype, ANIC32-051639): A. Front of head; B. Side of body; C. Top of body; D. Distribution of material examined.

\section{Calyptomyrmex ocullatus sp. $\mathbf{n}$.}

(Fig. 11)

Types. Holotype worker and 6 worker paratypes from Crystal Cascades near Cairns, Queensland, June-December 1956, Darlingtons (holotype ANIC32-047436; 1 paratype in ANIC, 4 paratypes in MCZC).

Diagnosis. Hairs on head and body thin (essentially the same width along entire length, or only slightly and gradually expanded distally, and with blunt tips), propodeum armed with short spines, mesonotum rugo-reticulate but lacking longitudinal rugae, petiolar node narrow and thick in dorsal view. This species is similar to grammus but differs in lacking longitudinal rugae on the mesonotum (these are present in grammus) and in having a narrower and thicker petiolar node.

Worker description. Mandibles striate basally, essentially smooth apically. Eyes small, with 2-3 ommatidia in greatest diameter. Propodeum in lateral view armed with short spines. Propodeal lobes slightly thickened posteriorly. Node of petiole in profile higher and larger than that of postpetiole. In dorsal view the petiolar node approximately the same width as the postpetiolar node. Head indistinctly rugose, the rugae tending to be longitudinal anteriorly and forming a weak network posteriorly, with the entire surface finely but distinctly punctate, the punctations partially obscuring individual rugae. Mesosoma and petiolar and postpetiolar nodes rugose superimposed 
over an indistinctly punctate background, the individual rugae wavy and sometimes forming a network, otherwise more or less linear. Gaster finely and indistinctly sculptured, stronger anteriorly and fading slightly posteriorly. Hairs on head and body erect, uniform in diameter and with sharply pointed tips. Clypeal fork with slightly enlarged and thin hairs, all hairs approximately the same length. Colour yellow-red, antennae, legs and base of gaster slightly lighter.

Measurements. Worker (holotype) - CFW 0.11; CI 95; HL 0.78; HW 0.74; ML 0.76; MTL 0.36; PetI 142; PetL 0.20; PetW 0.28; PronW 0.50; SI 63; SL 0.47.

Comments. This rare species has been collected only once, from a rainforest in Far North Queensland. No further details are available.

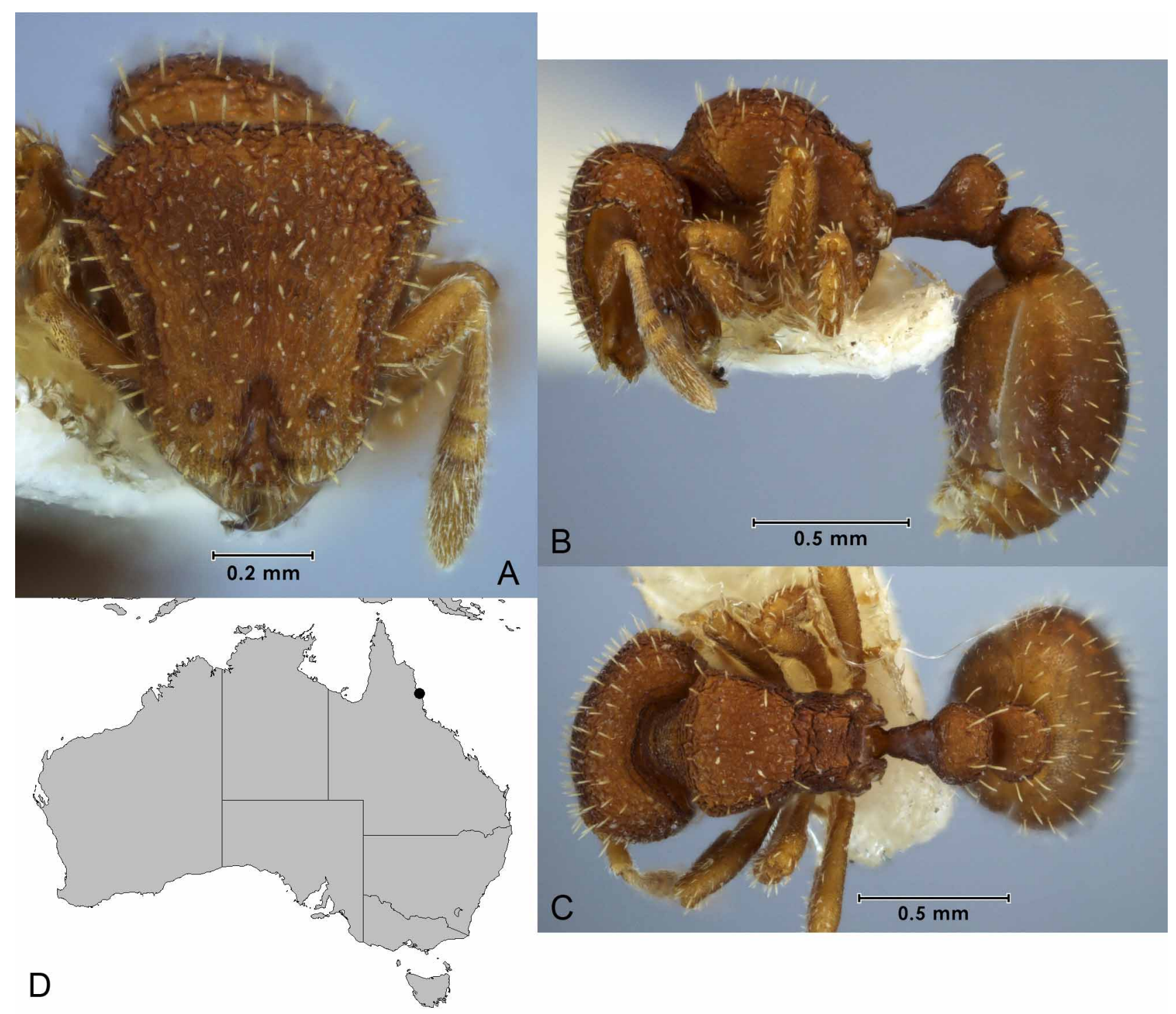

FIGURE 11. Calyptomyrmex ocullatus (holotype, ANIC32-047436): A. Front of head; B. Side of body; C. Top of body; D. Distribution of material examined.

\section{Calyptomyrmex rectopilosus Dlussky \& Radchenko}

(Fig. 12)

Calyptomyrmex rectopilosus Dlussky \& Radchenko, 1990: 124.

Type. Holotype worker from "Archipelago Baitylong, Isl. Dongho“, Quang Ninh Prov., Vietnam (UASK, examined). This island is also known as Dảo Dông Khoa, Ba Mùn Island and Cao Lô Island (and probably other names) and is located approx. 100km ENE Hải Phòng at approx. $21^{\circ} 00^{\prime} \mathrm{N} 107^{\circ} 35^{\prime} \mathrm{E}$. 
Diagnosis. Hairs on head and body thin (essentially the same width along entire length, or only slightly and gradually expanded distally, and with blunt tips), propodeum armed with moderately long, narrow spines, petiolar node leaning slightly posteriorly, the anterior face rounding into the dorsal face, in dorsal view broader than long; rugae on dorsum of head widely spaced, the underlying punctate surface clearly visible, the rugae fading posteriorly and essentially absent near the posterior margin. This species can be separated from others in this region by the thin body hairs, relatively long, narrow propodeal spines and the configuration of the cephalic sculpturing.

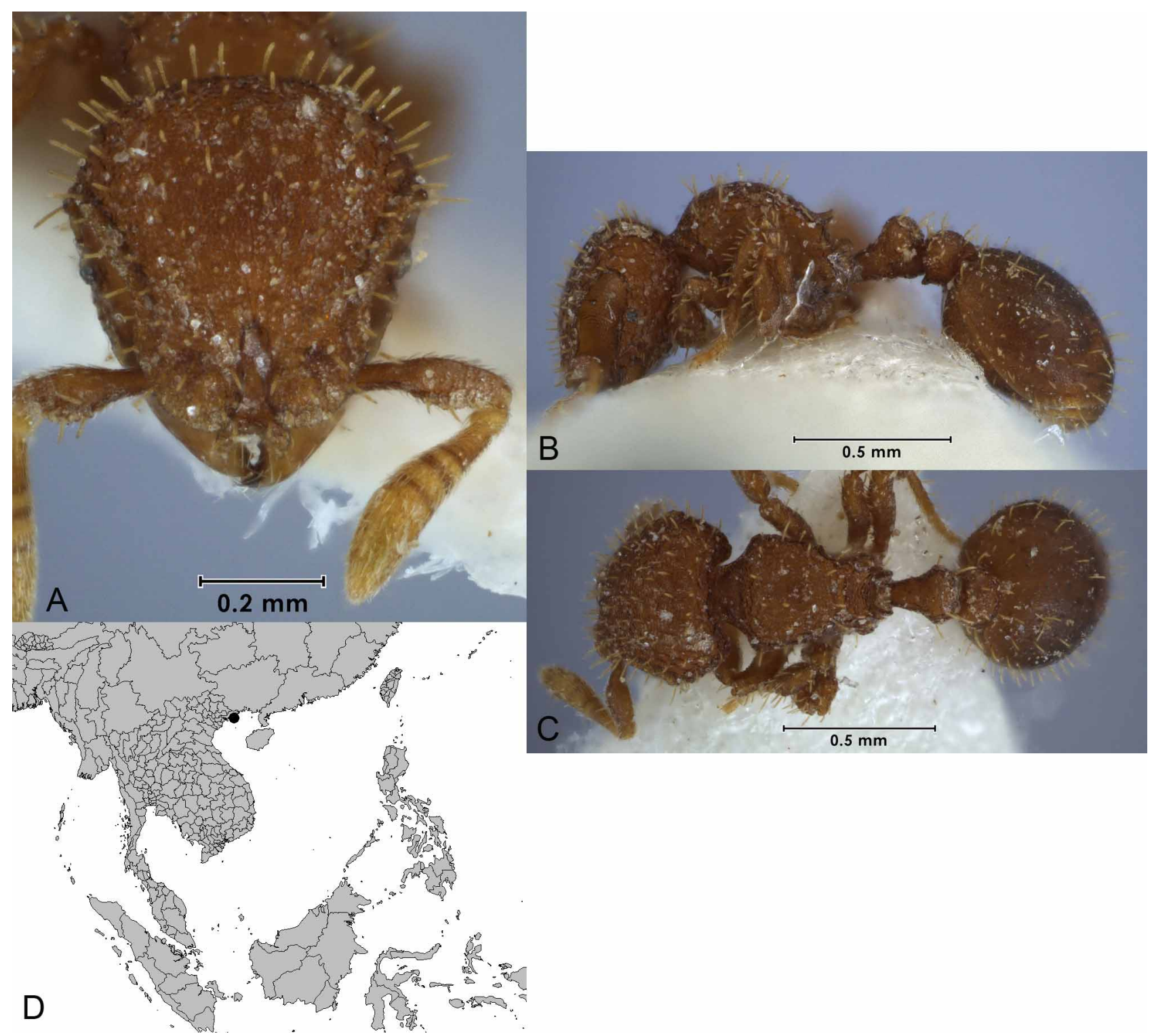

FIGURE 12. Calyptomyrmex rectopilosus (holotype): A. Front of head; B. Side of body; C. Top of body; D. Distribution of material examined.

Worker description. Mandibles striate basally, essentially smooth apically. Eyes small, with $2-3$ ommatidia in greatest diameter. Propodeum in lateral view armed with moderately long, narrow spines. Propodeal lobes uniform in thickness. Node of petiole in profile higher and narrower than that of postpetiole. In dorsal view the petiolar node similar in width to postpetiolar node. Head with widely spaced and indistinct rugae anteriorly, fading to essentially absent posteriorly, with the entire surface distinctly punctate. Upper section of mesosoma with irregular, wavy rugae superimposed over a punctate background; lower section of mesosoma (above legs), propodeum, petiole and postpetiole punctate. Gaster finely and indistinctly punctate and with a semi-matte appearance. Hairs on head and body erect, uniform in diameter and with sharp or blunt tips. Clypeal fork with short, thickened hairs basally and thin, elongate hairs distally. Colour yellow-red, the gaster slightly darker. 
Measurements. Worker (holotype) - CFW 0.10; CI 97; HL 0.63; HW 0.60; ML 0.57; MTL 0.25; PetI 163; PetL 0.12; PetW 0.20; PronW 0.40; SI 57; SL 0.35.

Comments. This is one of only two species currently known from the South-east Asian mainland (the other being beccarii). It has been encountered a number of times in Vietnam and is known to nest in rotten twigs and small fragments of rotten wood in well-developed forests (K. Eguchi, pers. comm.).

\section{Calyptomyrmex retrostriatus $\mathbf{s p} . \mathbf{n}$.}

(Fig. 13)

Types. Holotype worker and 2 worker paratypes from G. Matang, near Kuching, Sarawak, May 1994, Löbl (BMNH); 3 worker paratypes from Gn Matang, 20km W Kuching, Sarawak, 800m, 13 May 1994, Löbl \& Burckhardt, submontane forest (BMNH).

Diagnosis. Hairs on head and body thin (essentially the same width along entire length and with blunt tips) and sculpturing on gaster a series of widely spaced longitudinal striations. This species is most similar to lineolus in having thin body hairs and a heavily sculptured gaster, but differs in having the gaster entirely striate rather than consisting of a network anteriorly and striations posteriorly. Additionally, the body is body smaller (HW < $1.00 \mathrm{~mm})$ in the Malaysian-based retrostriatus while it is larger $(\mathrm{HW}>1.20 \mathrm{~mm})$ in the Australian lineolus.

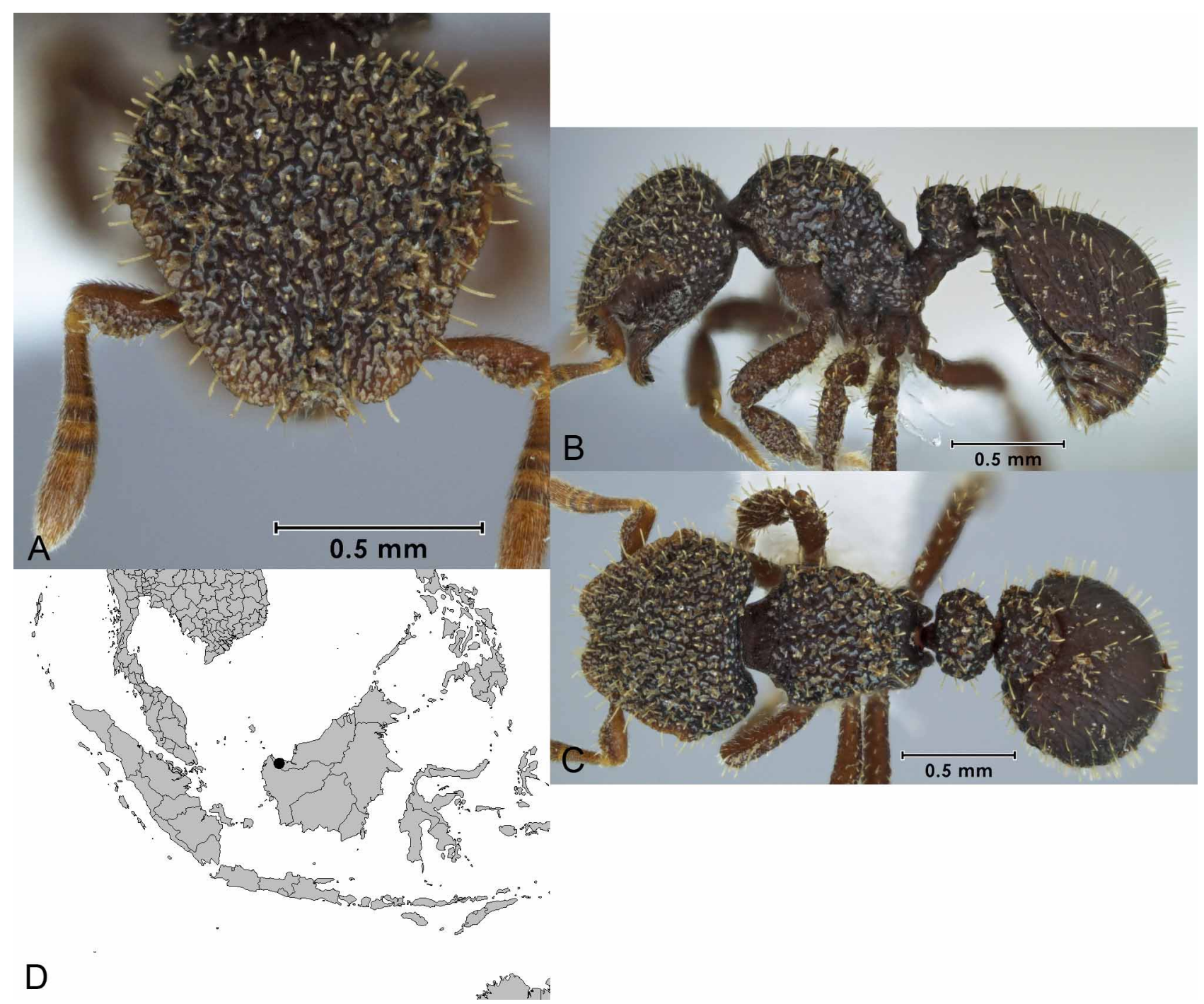

FIGURE 13. Calyptomyrmex retrostriatus (holotype): A. Front of head; B. Side of body; C. Top of body; D. Distribution of material examined. 
Worker description. Mandibles weakly striate basally, smooth distally (along masticatory margin). Eyes with 5-6 ommatidia in greatest diameter. Propodeum in lateral view with spines reduced to broad convexities and essentially absent. Propodeal lobes slightly thickened posteriorly. Node of petiole in profile slightly higher and narrower than postpetiole. In dorsal view the petiolar node slightly narrower than the postpetiolar node. Head indistinctly rugose, the rugae forming an indistinct network with the rugae more closely spaced anteriorly and more widely spaced posteriorly, and with the underlying surface finely but distinctly punctate. Mesosoma and petiolar and postpetiolar nodes with irregular, wavy rugae superimposed over an indistinctly punctate background. Gaster distinctly longitudinally striate. Hairs on head and body erect, uniform in diameter and with sharp or blunt tips. Clypeal fork with thin hairs only, the apical pair slightly thinner than the lateral pair. Colour red-brown, the antennae and legs slightly lighter.

Measurements. Worker $(\mathrm{n}=4)$ - CFW 0.13-0.15; CI 112-114: HL 0.78-0.85; HW 0.87-0.96; ML 0.86-0.96; MTL 0.37-0.41; PetI 162-178; PetL 0.22-0.24; PetW 0.36-0.41; PronW 0.58-0.65; SI 50-51; SL 0.45-0.49.

Comments. This rarely encountered species has been collected from a submontane forest in Sarawak. Nothing more is known of its biology.

\section{Calyptomyrmex ryderae sp. $\mathrm{n}$.}

(Figs 14, 18)

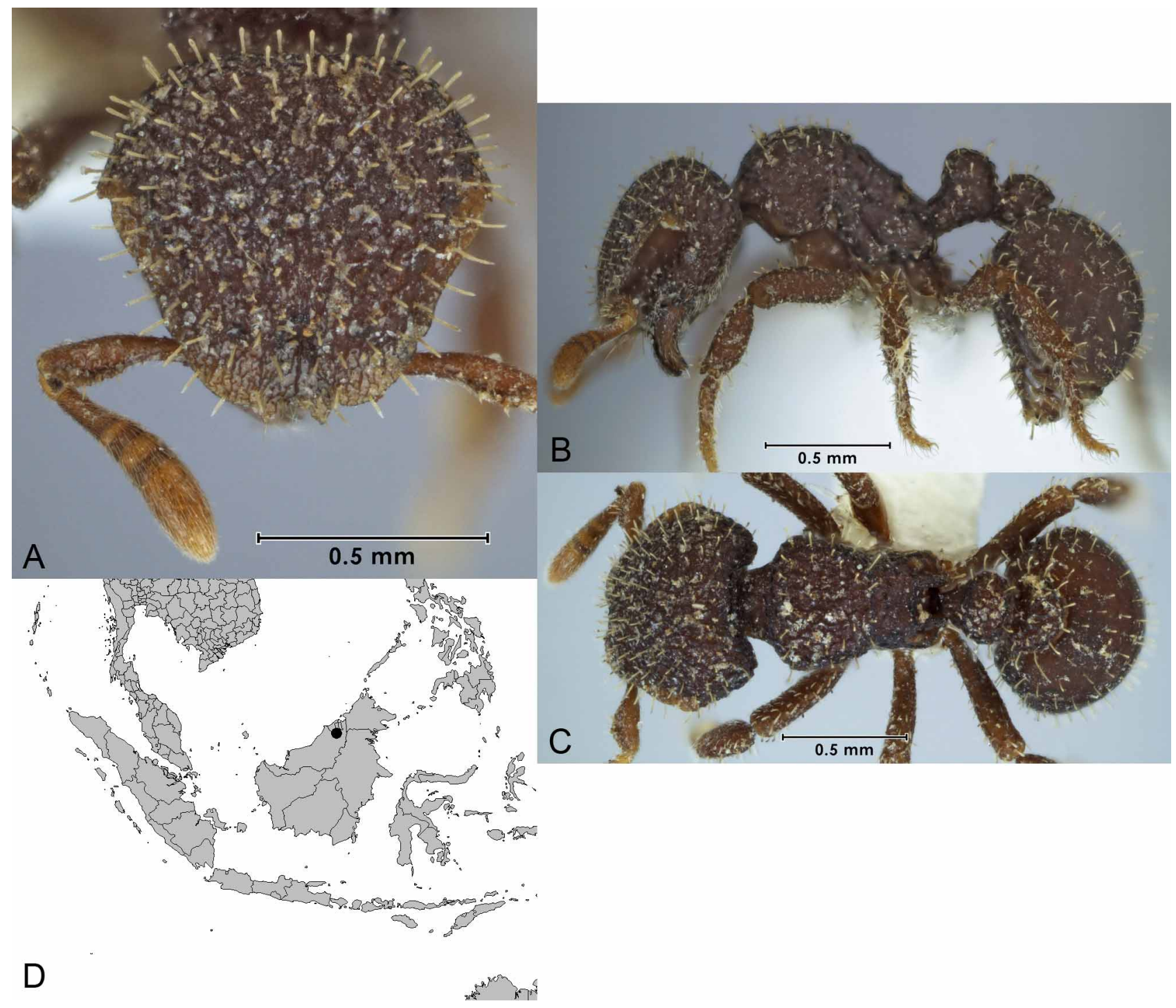

FIGURE 14. Calyptomyrmex ryderae (holotype): A. Front of head; B. Side of body; C. Top of body; D. Distribution of material examined. 
Types. Holotype worker from G. Mulu National Park, RGS Expedition, Long Pala, 4th Dist., Sarawak, Malaysia, 21 October 1977, B. Bolton, lowland rainforest, leaf litter (BMNH). Paratypes: 21 workers, same data as holotype except 5 workers collected 21 October, 11 workers collected 16 October, 1 worker collected 18 October, 1 worker collected 28 September, 1 worker collected 20 September (soil on rock), 1 worker collected 1 October (leaf litter on $\log ) ; 6$ workers from Gn. Mulu National Park, 4th Dist., Sarawak, Malaysia, June-August 1978, P.M. Hammond \& J.E. Marshall, B.M. 1978-49 (ANIC, BMNH).

Diagnosis. Hairs on head and body thin (essentially the same width along entire length and with blunt tips), gaster weakly punctate, propodeum lacking or essentially lacking spines or angles, petiolar node in dorsal view noticeably wider than long (PetI $>130$ ) and body smaller (HW $<1.05 \mathrm{~mm}$ ). This species is most similar to asper but differs in having the lateral surfaces of mesosoma and the dorsal surface of head with more numerous, narrower and more closely spaced rugae (the rugae are less numerous, broader and more widely spaced in asper), the hairs on the mesonotum are longer and thinner (they are shorter and tending to be weakly spatulate in asper), the petiolar node in dorsal view noticeably wider than long (PetI $>130$ ) while it is only slightly wider than long (PetI approx. 115 ) in asper, and the body is smaller ( $\mathrm{HW}<1.05 \mathrm{~mm}$ ) in ryderae compared to asper ( $\mathrm{HW}>1.05 \mathrm{~mm}$ ).

Worker description. Mandibles striate along entire length. Eyes with 5-6 ommatidia in greatest diameter. Propodeum in lateral view with spines reduced to broad angles and essentially absent. Propodeal lobes uniform in thickness. Node of petiole in profile higher than and approximately the same size as postpetiole. In dorsal view the petiolar node slightly narrower than the postpetiolar node. Head indistinctly rugose, the rugae forming an indistinct network, with the underlying surface finely but distinctly punctate. Mesosoma and petiolar and postpetiolar nodes with irregular, wavy rugae superimposed over an indistinctly punctate background. Gaster finely and indistinctly sculptured and with a matte appearance. Hairs on head and body erect, uniform in diameter and with sharp or blunt tips. Clypeal fork with thin hairs only, the apical pair slightly thinner than the lateral pair. Colour red-brown, the antennae and legs slightly lighter.

Measurements. Worker $(n=5)$ - CFW 0.14-0.15; CI 112-115: HL 0.79-0.89; HW 0.89-1.01; ML 0.87-1.00; MTL 0.38-0.45; PetI 134-155; PetL 0.19-0.23; PetW 0.30-0.34; PronW 0.56-0.63; SI 50-52; SL 0.45-0.51.

Comments. Calyptomyrmex ryderae is known from a handful of collections from a single lowland rainforest area of Sarawak. Most collections have been from leaf litter samples while one worker was found in soil on a rock.

\section{Calyptomyrmex sabahensis sp.n.}

(Fig. 15)

Types. Holotype worker from Quoin Hill, Tawau, Sabah, Malaysia, 16-19 June 1968, R. W. Taylor, rainforest, leafmould (ANIC32-051676). Paratypes: 20 workers, same data as holotype (4 workers, ANIC32-051672 (3 in ANIC, 1 in MCZC); 2 workers, ANIC 32-051673; 8 workers, ANIC 32-051674 (7 in ANIC, 1 in BMNH); 4 workers, ANIC 32-051675; 2 workers, ANIC32-053425).

Diagnosis. Hairs on head and body thin (essentially the same width along entire length, or only slightly and gradually expanded distally, and with blunt tips), gaster weakly (and sometimes indistinctly) punctate, propodeum armed with short, broad angles; setae on leading edge of scape long, about as long as scape width, legs rugo-reticulate. This combination of characters will separate this species from all others in the region.

Worker description. Mandibles striate basally, essentially smooth apically. Eyes small, with $2-3$ ommatidia in greatest diameter. Propodeum in lateral view armed with short, broad angles. Propodeal lobes thin anteriorly, thickened posteriorly. Node of petiole in profile slightly higher and slightly larger than that of postpetiole. In dorsal view the petiolar node narrower than the postpetiolar node. Head indistinctly rugose, the rugae longitudinal anteriorly and forming an indistinct network posteriorly, with the entire surface finely but distinctly punctate. Mesosoma and petiolar and postpetiolar nodes with irregular, wavy rugae superimposed over an indistinctly punctate background. Gaster finely and indistinctly sculptured and with a matte appearance. Hairs on head and body erect, uniform in diameter and with sharp or blunt tips. Clypeal fork with slightly enlarged and thin hairs, all hairs approximately the same length. Colour red-brown, antennae and legs slightly lighter.

Measurements. Worker ( $\mathrm{n}=8$ ) - CFW 0.12-0.14; CI 98-104; HL 0.73-0.79; HW 0.74-0.81; ML 0.71-0.79; MTL 0.32-0.36; PetI 130-147; PetL 0.18-0.21; PetW 0.24-0.30; PronW 0.50-0.53; SI 51-54; SL 0.40-0.43. 
Additional material examined. Malaysia: Sabah: Umas Umas nr. Tawau (Taylor,R.W.) (ANIC); mi.43 Labuk Rd. ex. Sandakan (Lungmanis) (Taylor,R.W.) (ANIC); mi.45 Labuk Rd. ex. Sandakan (Lungmanis) (Taylor,R.W.) (ANIC); Tawau (Waage,J.) (BMNH).

Comments. This species has been encountered a number of times in extreme north-eastern Borneo, always in rainforest leaf litter. Nothing further is known of its biology.

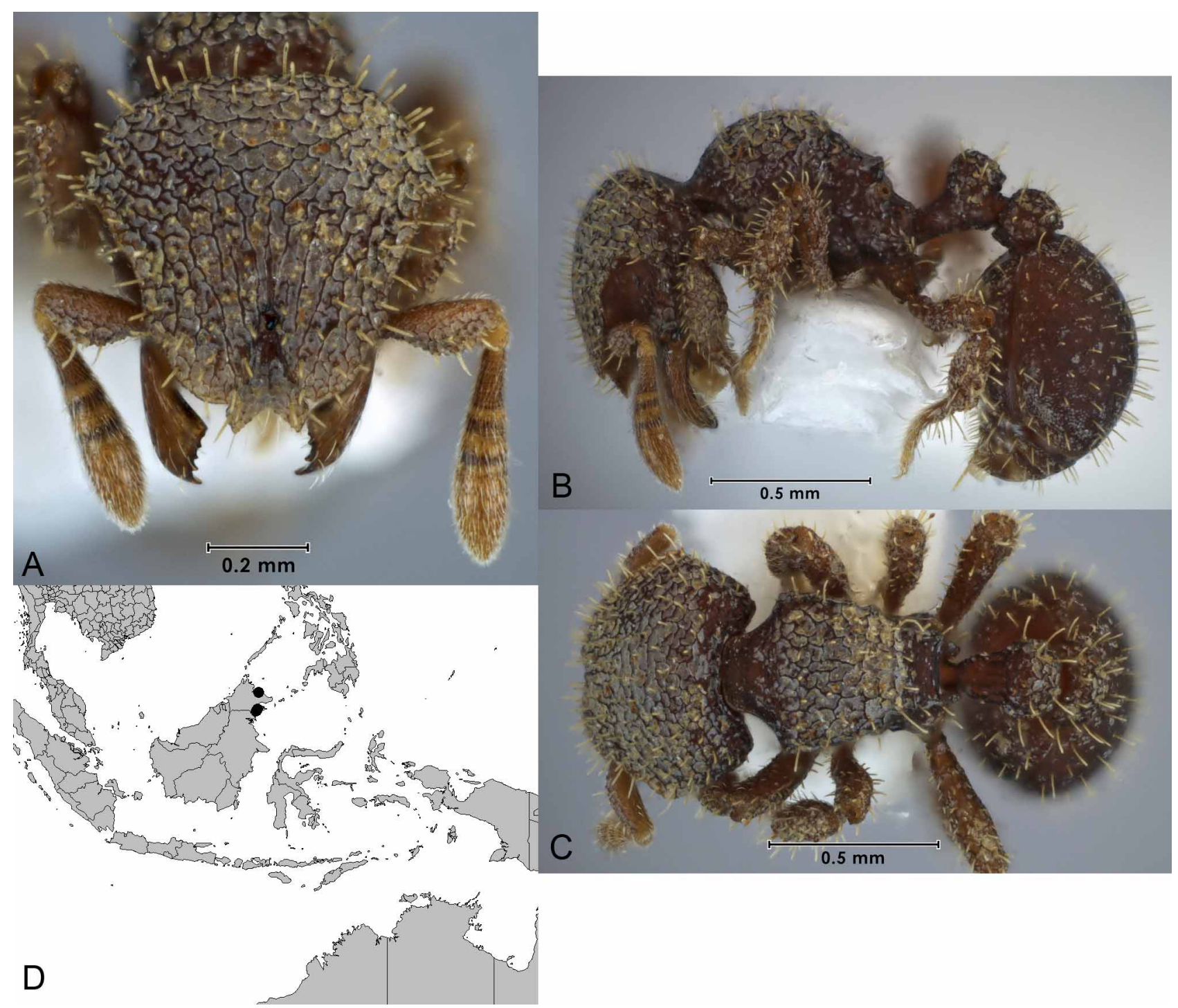

FIGURE 15. Calyptomyrmex sabahensis (holotype, ANIC32-051676): A. Front of head; B. Side of body; C. Top of body; D. Distribution of material examined.

\section{Calyptomyrmex sparsus sp. $\mathrm{n}$.}

(Figs 16, 18)

Types. Holotype worker and 1 worker paratype from upper Mulgrave Rd., Kearneys Falls, Queensland, 10 December 1988, Monteith \& Thompson, logs and trees (holotype ANIC32-053402, paratype ANIC32-047434).

Diagnosis. Hairs on head and body spatulate (noticeably narrower near the body and expanded distally and with a rounded tip), gaster weakly punctate (fading posteriorly), propodeum armed with low, angular spines, in dorsal view petiole only slightly broader than long and oval in shape, body larger (HW > 1.12) and head longer than broad $(\mathrm{CI}<98)$. This species is similar to fritillus but differs in having a larger body (HW $>1.12 \mathrm{~mm})$ and in dorsal view the petiole is only slightly broader than long and is oval in shape (in fritillus the body is smaller (HW < $0.82 \mathrm{~mm}$ ) and in dorsal view the petiole is much broader than long and rectangular in shape). It differs from the very 
similar danum in being larger $(\mathrm{HW}>1.12$ vs. $(\mathrm{HW}<1.12)$ and having the head longer than broad (CI < 98 vs. CI $>104$ in danum). For additional differences see Diagnosis under danum.

Worker description. Mandibles indistinctly striate. Eyes with 5-6 ommatidia in greatest diameter. Propodeum in lateral view with low, angular spines. Propodeal lobes uniform in thickness. Node of petiole in profile slightly higher and larger than that of postpetiole. In dorsal view the petiolar node slightly narrower than the postpetiolar node. Head with longitudinal, slightly wavy rugae which diverge and fade posteriorly and are superimposed over a punctate background. Promesonotum indistinctly foveolate, sides of mesosoma indistinctly rugose, entire mesosoma with a punctate background. Petiole, postpetiole and gaster punctate, the strength of the sculpture on the gaster fading slightly posteriorly. Hairs on head and body spatulate and appressed. Clypeal fork with spatulate hairs only. Colour dark red-brown, the legs and gaster slightly lighter.

Measurements. Worker $(\mathrm{n}=2)$ - CFW 0.25-0.27; CI 95-96; HL 1.20-1.21; HW 1.14-1.16; ML 1.25-1.26; MTL 0.65-0.66; PetI 127-143; PetL 0.26-0.28; PetW 0.35-0.37; PronW 0.78-0.78; SI 55-62; SL 0.64-0.71.

Comments. This rare species is known from a single collection of two workers encountered while pyrethrum fogging rainforest logs and trees.

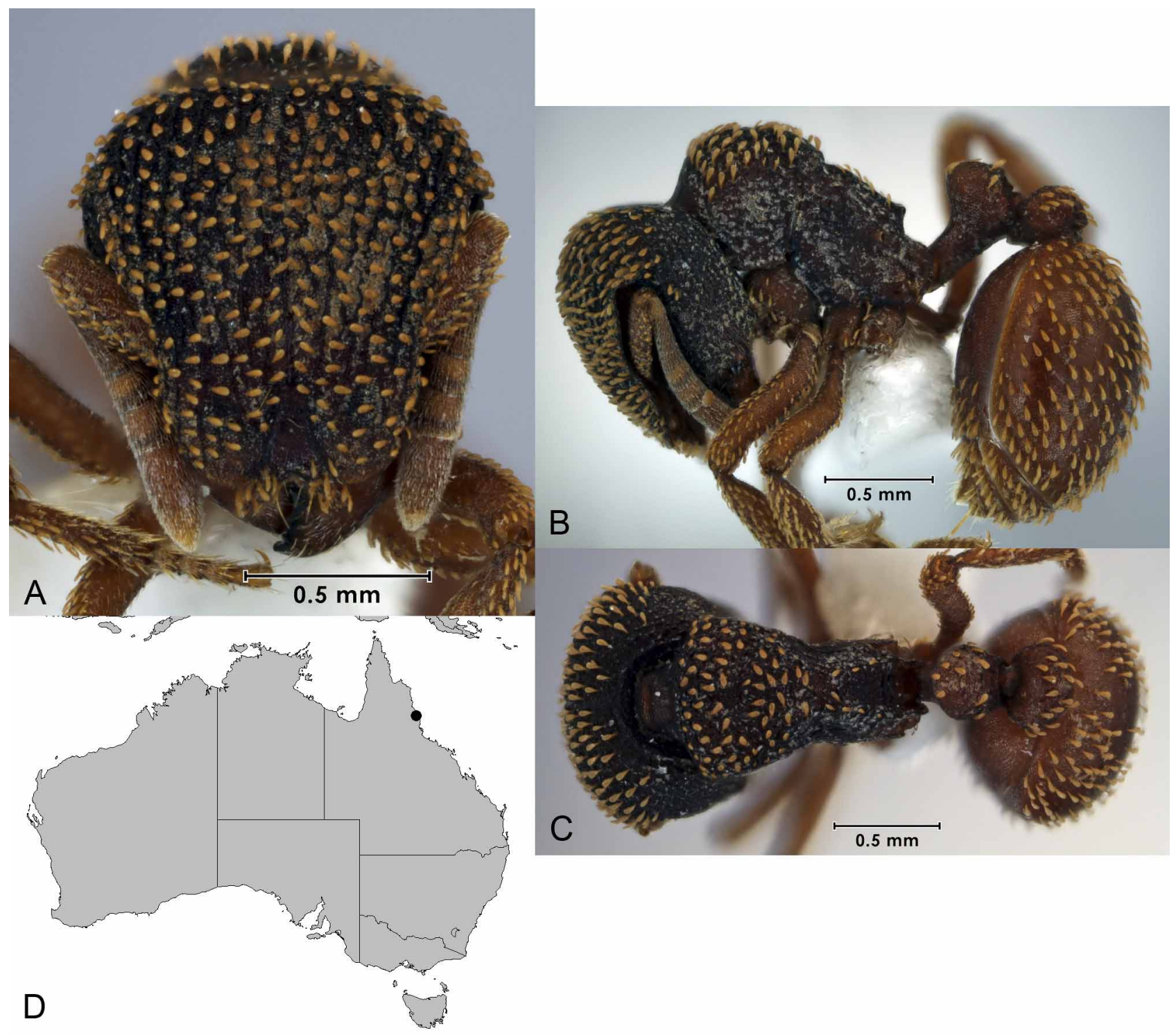

FIGURE 16. Calyptomyrmex sparsus (paratype, ANIC32-047434): A. Front of head; B. Side of body; C. Top of body; D. Distribution of material examined. 


\section{Calyptomyrmex taylori sp. $\mathbf{n}$.}

(Figs 17, 18)

Types. Holotype worker and 1 worker paratype from 3.0km W Cape Tribulation (Site 6), Queensland, 20 September 1982, rainforest, sieved litter, Monteith, Yeates \& Thompson (holotype ANIC32-051625, paraytype ANIC32053403). Paratypes: 2 workers, same data as holotype except 19 September 1982 (ANIC32-051626 (1 in ANIC, 1 in MCZC)); 1 worker, same data as holotype except 2 October 1982 (ANIC32-051627).

Diagnosis. Hairs on head and body spatulate (noticeably narrower near the body and expanded distally and with a rounded tip), gaster indistinctly punctate, propodeum unarmed, in dorsal view node of petiole rectangular, body smaller (HW $<0.85 \mathrm{~mm}$ ). Within Australia, taylori is most similar to beccarii but differs in having narrower spatulate hairs on the head, a more rectangular petiolar node (in dorsal view) and in being smaller ( $\mathrm{HW}<0.85 \mathrm{~mm}$ rather than $>0.90 \mathrm{~mm})$.

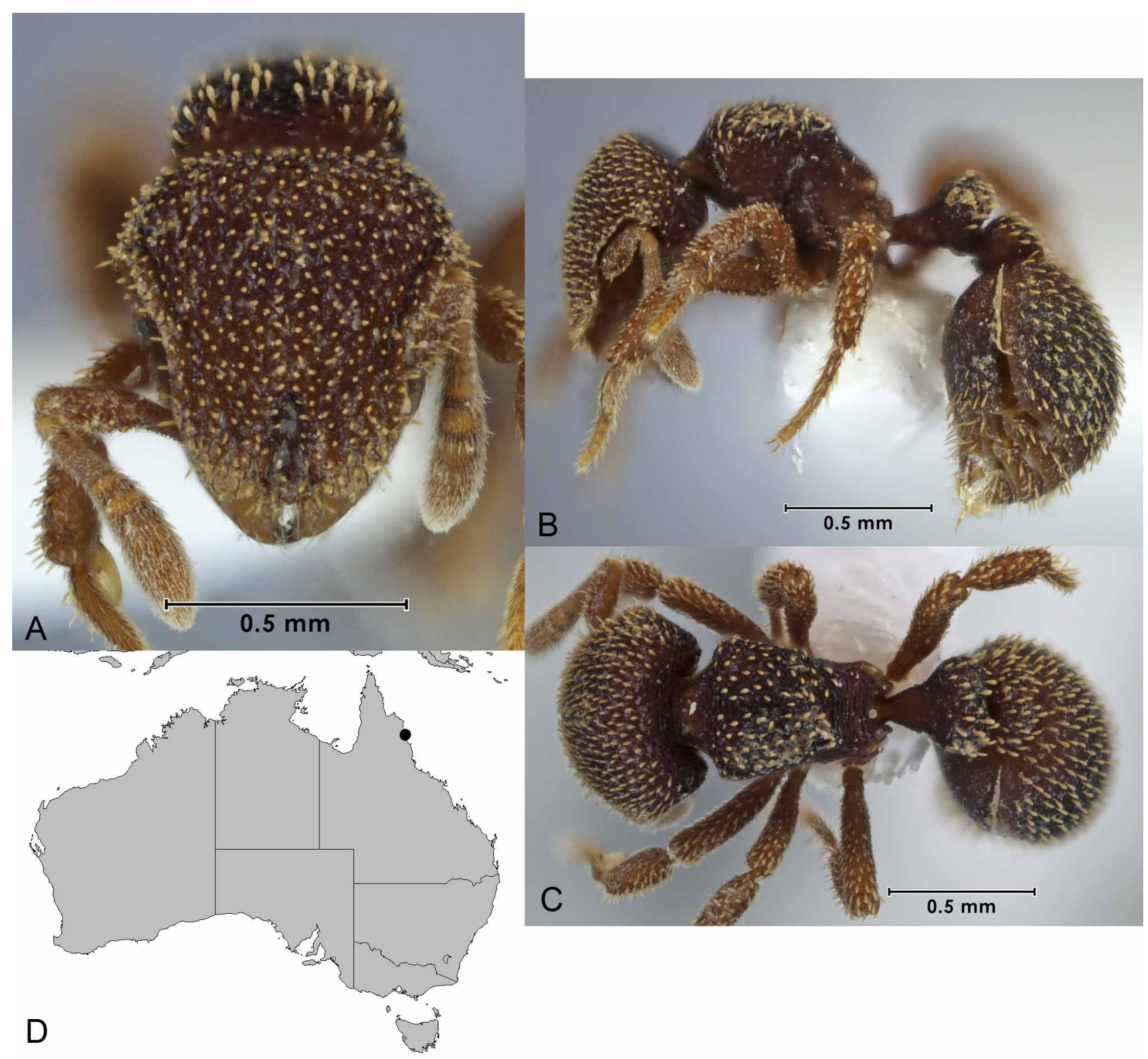

FIGURE 17. Calyptomyrmex taylori (holotype, ANIC32-051625): A. Front of head; B. Side of body; C. Top of body; D. Distribution of material examined.

Worker description. Mandibles striate. Eyes with 4-5 ommatidia in greatest diameter. Propodeum in lateral view lacking angles or spines. Propodeal lobes thin anteriorly, thickened posteriorly. Node of petiole in profile slightly higher and larger than that of postpetiole. In dorsal view the petiolar node much broader than long and 
slightly narrower than postpetiolar node. Head weakly rugose, the rugae enclosing foveolate spaces, the underlying surface indistinctly punctate. Promesonotum, sides of mesosoma and dorsum of petiole and postpetiole with illdefined longitudinal rugae which are slightly stronger laterally than dorsally. The underlying surface of the mesosoma, petiole, postpetiole and gaster indistinctly punctate. Hairs on head and body narrowly spatulate and raised above the surface of the body. Clypeal fork with enlarged, short and thin, elongate hairs. Colour dull red-brown, antennae and legs slightly lighter.

Measurements. Worker $(\mathrm{n}=10)$ - CFW 0.09-0.11; CI 92-97; HL 0.76-0.83; HW 0.72-0.80; ML 0.70-0.81; MTL 0.31-0.38; PetI 174-201; PetL 0.17-0.20; PetW 0.33-0.36; PronW 0.49-0.55; SI 58-64; SL 0.44-0.51.

Additional material examined (ANIC). Australia: Queensland: $1.5 \mathrm{~km}$ EbyN Mt. Sorrow (Calder,A. \& Weir,T.), $1.5 \mathrm{~km}$ W Cape Tribulation (Site3) (Monteith, Yeates \& Thompson), 2.0km WNW Cape Tribulation (Site 2) (Monteith, Yeates \& Thompson; Monteith,G.B.; Monteith,G.B. \& Yeates,D.K.), 3.5km W Cape Tribulation (Site 7) (Monteith, Yeates \& Thompson; Monteith,G.B.), Mt. Sorrow summit, Cape Tribulation (Monteith,G.B.), Noah Creek (Taylor \& Feehan), nr. Cape Tribulation (Taylor,R.W. \& Feehan,J.).

Comments. Calyptomyrmex taylori is known from numerous collections made within a tiny area near Cape Tribulation, Cape York Peninsula, Queensland. All collections have been from rainforest leaf litter.

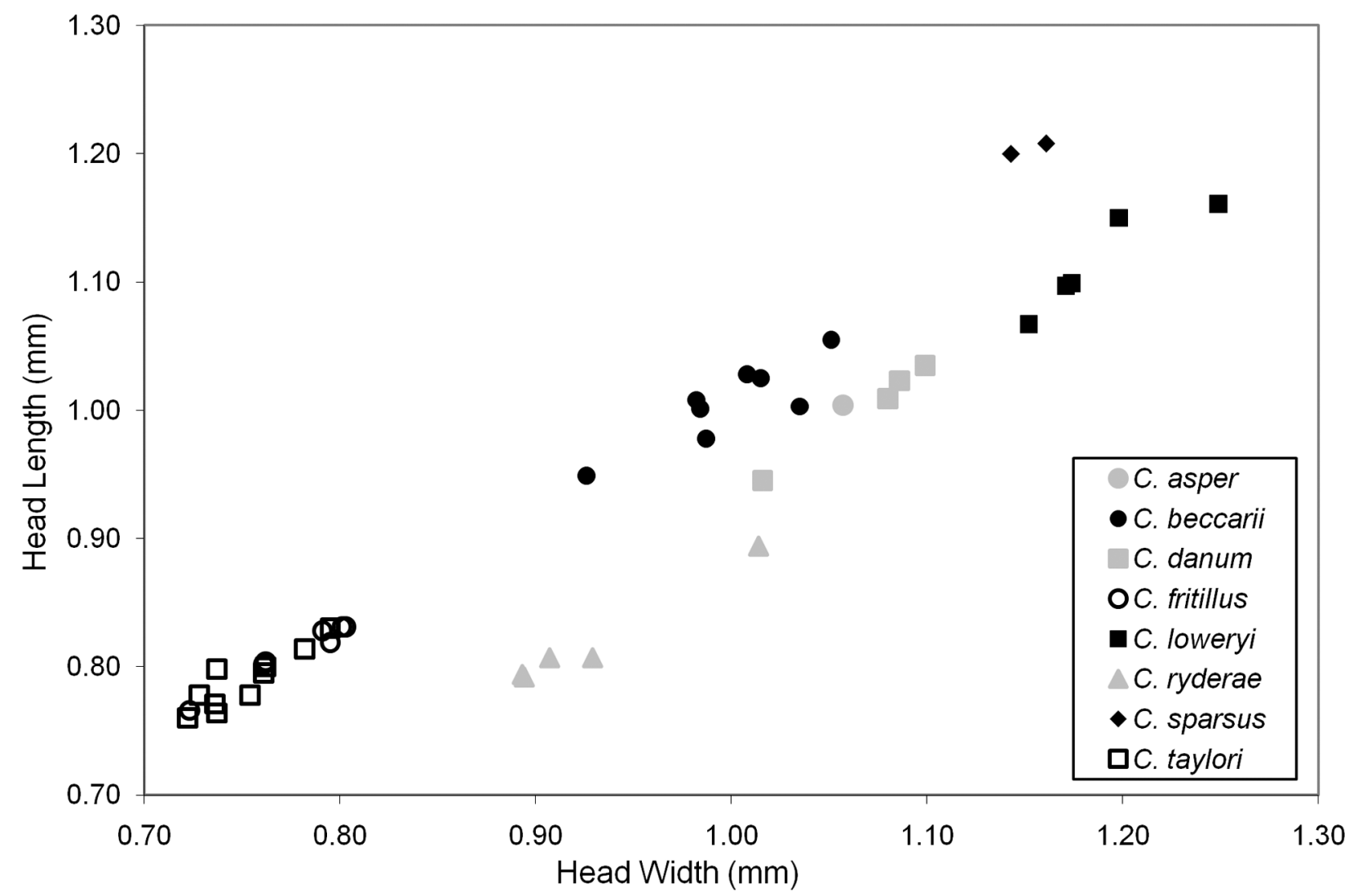

FIGURE 18. Head length versus head width for C. asper, C. beccarii, C. danum, C. fritillus, C. loweryi, C. ryderae, C. sparsus and C. taylori.

\section{Acknowledgements}

I would like to thank Natalie Barnett and Robyn Meier for technical support during this project. For loans of material, I thank Barry Bolton and Sue Ryder (The Natural History Museum, London), Chris Burwell (Queensland Museum, Brisbane), Stefan Cover and Gary Alpert (Museum of Comparative Zoology, Harvard University), David General, Christiana Klingenberg (Staatliches Museum für Naturkunde Karlsruhe, www.anttypes.org), Bernhard Merz (Muséum d'histoire naturelle, Geneva), Fabio Penati (Museo Civico di Storia Naturale "Giacomo Doria", Genoa), Alex Radchenko (Ukrainian Academy of Science, Kiev and Polish Academy of Sciences) and Bob Taylor 
(ANIC, Canberra). Helpful comments on the manuscript were received from Barry Bolton, Katsuyuki Eguchi and Eli Sarnat. This project was supported by CSIRO Ecosystem Sciences and the Commonwealth Environment Research Facilities Taxonomy Research \& Information Network.

\section{References}

Baroni Urbani, C. (1975) Primi reperti del genere Calyptomyrmex Emery nel subcontinente Indiano. Entomologica Basiliensia, $1,395-411$.

Bolton, B. (1981) A revision of the ant genera Meranoplus F. Smith, Dicroaspis Emery and Calyptomyrmex Emery (Hymenoptera: Formicidae) in the Ethiopian zoogeographical region. Bulletin of the British Museum (Natural History). Entomology, 42, 43-81.

Bolton, B., Alpert, G., Ward, P.S. \& Naskrecki, P. (2006) Bolton's Catalogue of Ants of the World: 1758-2005. Harvard University Press, Cambridge, Massachusetts (CD-ROM).

Brown, W.L., Jr. (1949) Revision of the ant tribe Dacetini. 4. Some genera properly excluded from the Dacetini, with the establishment of the Basicerotini, new tribe. Transactions of the American Entomological Society, 75, 83-96.

Brown, W.L., Jr. (1951) New synonymy of a few genera and species of ants. Bulletin of the Brooklyn Entomological Society, 46, 101-106.

Dlussky, G.M. \& Radchenko, A.G. (1990) The Ants (Hymenoptera, Formicidae) of Vietnam. Subfamilies Pseudomyrmicinae and Myrmicinae (tribes Calyptomyrmecini, Meranoplini and Cataulacini), pp. 119-125 in Akimov, I.A., Emelianov, I.G. \& Zerova, M.D. (eds.). News of Faunistics and Systematics, Kiev (Naukova Dumka) [in Russian].

Donisthorpe, H. (1949a) A new genus and species of dacetine ant from New Guinea. Entomologist's Monthly Magazine, 84 (1948), 281.

Donisthorpe, H. (1949b) A species of Calyptomyrmex Emery from New Guinea. Entomologist's Monthly Magazine, 85, 186.

Emery, C. (1887) Catalogo delle formiche esistenti nelle collezioni del Museo Civico di Genova. Parte terza. Formiche della regione Indo-Malese e dell'Australia (continuazione e fine). Annali del Museo Civico di Storia Naturale di Genova, (2) 5 [25], 427-473.

Forel, A. (1901) Formiciden des Naturhistorischen Museums zu Hamburg. Neue Calyptomyrmex, Dacryon, Podomyrma, und Echinopla-Arten. Jahrbuch der Hamburgischen Wissenschaftlichen Anstalten, 18, 45-82.

Guenard, B. (2009) Ant genera of the world. http://www.antmacroecology.org/ant_genera/Calyptomyrmex.php (visited 21 December 2009).

Hölldobler, B. \& Wilson, E.O. (1986) Soil-binding pilosity and camouflage in ants of the tribes Basicerotini and Stegomyrmecini (Hymenoptera, Formicidae). Zoomorphology (Berl.), 106, 12-20.

Shattuck, S.O. (1999) Australian Ants: Their biology and identification. Monographs in Invertebrate Taxonomy, 3, 1-226.

Taylor, R.W. (1991) Nomenclature and distribution of some Australasian ants of the Myrmicinae. Memoirs of the Queensland Museum, 30, 599-614.

Wheeler, W.M. (1919) The ants of Borneo. Bulletin of the Museum of Comparative Zoology, 63, 43-147. 